\title{
Externalidades ambientales y resiliencia lacustre en la Ciénega de Chignahuapan, México
}

\section{Environmental externalities and lacustrine resilience in the Cienega de Chignahuapan, Mexico}

Recibido: enero 03 de 2019.

María Estela Orozco-Hernández*

Gratia Deii Flores-Salgado**

Ilse Ibeth Díaz-Ramírez***

Aceptado: diciembre 16 de 2019

\section{Resumen}

Este estudio analiza los conflictos que producen los modos de apropiación de los recursos naturales y las externalidades ambientales que alteran las funciones ecosistémicas de la Ciénega de Chignahuapan o Atarasquillo. Se utilizó literatura, documentos oficiales, estadísticas y cartografía, la observación in situ y la información oral de los actores sustenta la base empírica de la investigación. Las externalidades regionales que amenazan la estabilidad del cuerpo lacustre expresan cambios de uso de suelo, disminución de los servicios hídricos del bosque, contaminación de afluentes, construcción de vialidades regionales, actividad industrial, re densificación demográfica, urbanización y sub urbanización. Las externalidades locales manifiestan alteración del régimen hidrológico, quemas de tule, introducción de peces exóticos, contaminación por descargas residuales crudas, proliferación de malezas terrestre y acuática, transferencia de los derechos de la actividad cinegética y aprovechamiento de subsistencia de los recursos lacustres. La presión exhibe un escenario desalentador que anticipa descenso de la capacidad natural del ecosistema lentico para superar las externalidades negativas. La visión sostenible prescribe estrategias de colaboración, autogestión y regulación, con el objeto de que las industrias acaten la responsabilidad ambiental para tratar y conservar el agua; los gobiernos incrementen la capacidad de tratamiento de aguas residuales y los usuarios mejoren el uso y cuidado del recurso. En las unidades de manejo monitorear el cumplimiento de la conservación, aplicar la ley en materia cinegética y prácticas ilegales, regular el arrendamiento cinegético por terceros, recuperar el conocimiento tradicional y desarrollar proyectos alternativos que moderen el uso de los recursos lacustres. Palabras clave: Externalidades, resiliencia, Ciénega, apropiación, recursos naturales.

\footnotetext{
Abstract

This study analyzes the conflicts produced by the modes of appropriation of natural resources and environmental externalities that alter the ecosystem functions of the Cienega de Chignahuapan or Atarasquillo. Literature, official documents, statistics and cartography were used, the observation in situ and the oral information of the actors supports the empirical basis of the research. Regional externalities that threaten the stability of the lake body express changes in land use, decrease in forest water services, pollution of tributaries, and construction of regional roads, industrial activity, population densification, urbanization and sub urbanization. Local externalities manifest alteration of the hydrological regime, tule tree burning, introduction of exotic fish, contamination by raw residual discharges, proliferation of terrestrial and aquatic weeds, transfer of the rights of hunting activity and use of subsistence of lake resources. The pressure exhibits a daunting scenario that anticipates a decrease in the natural capacity of the slow ecosystem to overcome negative externalities. The sustainable *Universidad Autónoma del Estado de México, Facultad de Planeación Urbana y Regional, México, **Universidad Nacional Autónoma de México, ${ }^{* * *}$ Consejo Estatal de Población del Estado de México, México. Correo electrónico: eorozcoh61@hotmail.com.
} 
vision prescribes strategies for collaboration, self-management and regulation, so that the industries comply with the environmental responsibility to treat and conserve water; Governments increase wastewater treatment capacity and users improve the use and care of the resource. In the management units, monitor compliance with conservation, apply the law on hunting and illegal practices, regulate hunting for third parties, recover traditional knowledge and develop alternative projects that moderate the use of lake resources.

Keywords: externalities, resilience, Cienega, appropriation, natural resources.

\section{Introducción}

Las externalidades derivadas de las interrelaciones de los sistemas económico, físico y social expresan que los patrones de crecimiento y consumo de la población ejercen cada vez más presión sobre los ecosistemas (WWF, 2016: 74). El aseguramiento de los servicios ecosistémicos, la reducción de las reservas ecológicas, la acumulación de desechos y los modos de aprovechamiento son temas clave en el debate actual de la sostenibilidad (Galli et al., 2017: 383). Mantener condiciones ambientales apropiadas para sostener la vida en un territorio y el impulso de actividades productivas suelen presentarse como propósitos irreconciliables (Gálvez, 2012).

Los intereses y las necesidades sociales racionalizan los modos de apropiación y las prácticas de aprovechamiento de los recursos naturales; la apropiación de la naturaleza se realiza a través del proceso social del trabajo (Young, 2009); las prácticas de aprovechamiento que pueden ser favorables para un sistema podrían ser desfavorables para otros; cualquier actividad humana genera externalidades que afectan a los sistemas ecológicos y a los sistemas productivos (Miró, 2002).

En la sociedad actual, la explotación de los recursos naturales que proveen los ecosistemas se encuentra vinculada a las conductas que fortalecen el valor de uso y conductas unidas a los valores de la vida urbana, las transacciones por dinero y la lucha por el poder (Salazar, 2000). La sobre explotación de los recursos naturales por encima de la capacidad de regeneración natural tiene repercusiones que conducen a la degradación del ambiente. El ambiente que rodea las formas de vida natural y social integra estructuras materiales e inmateriales, interacciones, funciones, procesos, valores, creencias, conductas y prácticas en espacio y tiempo determinado. Las relaciones formales e informales del sistema social determinan la transformación funcional de los ecosistemas y las tendencias de adaptación a las presiones del entorno.

En condiciones de degradación, los actores sociales resignifican las expectativas, las estrategias y las decisiones para ajustarse a los cambios ambientales y los ecosistemas pierden capacidad para realizar sus funciones vitales. El ajuste a las presiones del entorno remite a las nociones de autopoiesis y resiliencia; la primera define la capacidad de los sistemas vivos para auto producirse; esto depende de que conserven su estructura y organización. Las presiones naturales o inducidas traen cambios estructurales y nuevas interacciones que podría llevar a la desintegración y muerte, o a la reorganización y adaptación al entorno (Maturana \& Varela, 2007, Gibert et al., 2001). 
La resiliencia es la propiedad o capacidad intrínseca de los sistemas naturales y sociales para absorber el estrés o la presión ambiental, reorganizarse ante las perturbaciones, mantener las funciones vitales y adaptarse en condiciones de contingencia (Villalba, 2004). Este enfoque sitúa la permanencia de las ciudades, los entornos rurales y los ecosistemas de los que se sirven. Quintero (2016: 2) señala que la explotación de los recursos naturales genera consecuencias ecológicas a distintas escalas, desde lo local a lo regional y global; los cambios negativos destacan el deterioro de los paisajes y ecosistemas alterando su funcionamiento $\mathrm{y}$, a su vez, las formas de uso de la naturaleza por parte de las poblaciones locales.

Rathe (2017: 2) identifica ejemplos de los cambios de estados alternativos no deseados: las transiciones de los arrecifes de coral a las algas cubiertas de rocas, desde praderas hasta paisajes dominados por arbustos y los lagos de agua dulce con aguas claras a las aguas turbias. Los estados alternativos no deseados se asocian a los cambios en la oferta de servicios de los ecosistemas; por ejemplo, las oportunidades de producción de pescado, el potencial de pastoreo, el turismo y la recreación. Martínez (2004: 28), a través de los enfoques de la ecología política y la economía ecológica, problematiza los conflictos ecológico-distributivos o conflicto de "justicia ambiental" que resultan de la distribución inequitativa de los beneficios y los costos sociales de los impactos que las actividades económicas generan en los ecosistemas, entre otros, los conflictos por el uso y la del agua.

Los estudios sobre las Ciénegas del Lerma desde el punto de vista cultural y ecológico (Sugiura, 1998, Sugiura, 2000; Patrick, 2012; González \& Velasco, 2015), el impacto ecológico y cultural (Albores, 1995, González \& Velasco, 2015) y los problemas de la contaminación, los cambios de uso de suelo y la pérdida de biodiversidad (Velasco, 2008; Zepeda et al., 2012a; Zepeda et al. 2012b) centran la indagación en la Ciénega de Chiconahuapan o Almoloya, ubicada en los municipios de Almoloya del Río, Santa Cruz Atizapán y San Mateo Texcalyacac. La ficha de humedales de Ramsar (Ceballos, 2003: 1) distingue las Ciénegas de Chiconahuapan o Almoloya, Chimaliapan o Lerma y Chignahuapan o Atarasquillo. La presente investigación trata de la Ciénega de Chignahuapan o Atarasquillo, la cual identifica el polígono tres del área de protección de flora y fauna, Ciénegas del Lerma con una superficie de 346 hectáreas (DOF, 2002). Esta Ciénega, en lo particular, ha sido poco estudiada; está sujeta a una categoría de manejo que permite el aprovechamiento cinegético y en donde las economías de subsistencia extraen recursos lacustres. El entorno de las actividades económicas y agropecuarias, de la industria, de los asentamientos urbanos y suburbanos configuran la presión que las actividades humanas ejercen en el cuerpo lacustre. El enfoque de la economía ecológica, que coloca énfasis en las relaciones entre las actividades económicas y el medio natural, constituye el marco para analizar las externalidades ambientales que afectan la resiliencia o capacidad de adaptación natural de la Ciénega en estudio. 


\section{Métodos y materiales}

La investigación tiene un diseño no experimental transeccional, el cual permitió interpretar los rasgos particulares de la situación ambiental en un momento y lugar concretos a través de la observación directa y la opinión de los actores sociales (Hernández et al., 2006).

La interrogante que delimita el estudio plantea saber ¿cómo las externalidades ambientales afectan la capacidad de recuperación natural de la Ciénega Chignahuapan, Atarasquillo?

La metodología cualitativa partió de la pregunta de investigación y de la utilidad de los estudios transeccionales para tomar decisiones. El procedimiento consta de dos partes; en la primera se analizaron documentos oficiales, literatura específica para construir el contexto teórico e histórico-social del objeto de estudio y el problema ambiental. Para caracterizar los conflictos ambientales, se analizaron registros históricos de la propiedad social, información de los censos de población, cartografía, leyes federales y programas estatales.

En la segunda parte, el trabajo de campo fue sustancial; se hicieron recorridos en el periodo 2015-2017, y se realizaron entrevistas abiertas aplicadas a las autoridades de la Comisión Nacional de Áreas Naturales Protegidas (CONANP) y a los representantes de los ejidos que tienen derechos sobre la Ciénega. Con el objeto de recuperar las vivencias y los testimonios de los usuarios del cuerpo lacustre, se realizó la exploración etnográfica de las actividades de subsistencia; consistió en observación directa y entrevistas en profundidad, las cuales se aplicaron aleatoriamente basándose en la relación que los pobladores que practican la caza, la pesca y la recolección tuvieran con los recursos lacustres. Además, se tomaron notas, grabación de entrevistas y fotografías.

\section{Precedentes estructurales de los cambios ambientales}

Este apartado analiza los factores estructurales del cambio ambiental en el lago del Valle de Toluca; la superficie cubría alrededor de 35 mil hectáreas; a lo largo del siglo XIX, perdió 23,976 hectáreas, es decir, 89\% de la superficie original. Actualmente, cubre menos de 3,500 hectáreas, 61\% inundadas, distribuidas en las Ciénegas Chiconahuapan o Almoloya, Chimaliapan o Lerma y Chignahuapan o Atarasquillo (Ceballos, 2003; Velasco, 2008; CEPANAF, 2019).

El origen de los cambios tiene referente en el modo de vida que se sostenía en el aprovechamiento de los manantiales y los recursos acuáticos a través de la caza, la pesca y la recolección (Albores, 1995: 133) y el intercambio comercial con la población de tierra firme (Sugiura, 2000: 32). El nuevo control sociocultural rompe el circuito de aprovechamiento acuático-terrestre integrado por la experiencia, las pautas de vida y las decisiones de una cultura particular (Giménez, 1999), lo cual incorporó a los pobladores 
como fuerza de trabajo en el modelo productivo que concentró la tierra, los bosques y el agua; después de tres siglos, las haciendas se convertirían en eje de la producción de materias primas (Rojas, 1990: 16). Las tierras cenagosas quedaron en propiedad de las haciendas San Antonio de Padua (Doña Rosa), el Cerrillo, San Nicolás Peralta y sus anexos, Santa Catarina, Cocoapan y los ranchos de Alta Empresa, Amomolulco y Mayorazgo. Los dueños usaban las tierras para pastoreo de ganado, las rentaban y concedían permiso a los vecinos de los pueblos de San Pedro Totoltepec, Lerma y San Mateo Atarasquillo para pescar, cazar y cortar tule; en retribución, trabajaban como peones en el cultivo de la tierra (Camacho, 2007: 33).

Al promulgarse la Ley Agraria del 6 de enero de 1915, el reparto agrario institucionalizó el sistema de producción campesino en todo el país; hasta nuestros días, se caracteriza por la posesión de parcelas reducidas, manejo individual de la tierra, organización familiar y cultivo de maíz para autoconsumo.

En la primera mitad del siglo veinte, en la región del alto Lerma, existían veintidós propiedades de más de mil hectáreas; éstas fueron afectadas para crear noventa y siete ejidos; entre ellos, once en el actual municipio de Lerma. Los derechos sobre la tierra y el agua fueron conferidos a través de dotación y ampliación a los ejidos de San Nicolás Peralta, San José del Llanito, San Lorenzo Huitzizilapan (Amomolulco) y San Antonio de los Llanitos, la afectación recayó en la hacienda de San Nicolás Peralta de propiedad de Ignacio de la Torre y Mier, luego propiedad del Gobierno del Estado de México.

En 1937 se otorgaron 153 hectáreas de tierras cenagosas al ejido de San Nicolás Peralta; los ejidatarios de San José del Llanito obtuvieron autorización del gobierno estatal para pastorear ganado y cultivar maíz en los terrenos en desecación; las tierras inundables alejadas de los poblados de Amomolulco y San Antonio de los Llanitos se utilizaban irregularmente (cuadro 1).

Cuadro 1. Dotación de tierras a los núcleos ejidales, Ciénega de Chignahuapan, Atarasquillo

\begin{tabular}{|c|c|c|c|c|c|c|c|c|c|c|c|}
\hline \multirow{3}{*}{$\begin{array}{l}\text { Ejido } \\
\text { dotación }\end{array}$} & \multirow{3}{*}{$\begin{array}{l}\text { Resolución } \\
\text { presidencial }\end{array}$} & \multirow{3}{*}{$\begin{array}{l}\text { Posesión } \\
\text { definitiva }\end{array}$} & \multirow{3}{*}{$\begin{array}{l}\text { Poblado } \\
\text { Habitantes }\end{array}$} & \multicolumn{2}{|c|}{ Beneficiarios } & \multicolumn{6}{|c|}{ Superficie en hectáreas } \\
\hline & & & & Con & $\operatorname{Sin}$ & Riego & Temporal & Pastal & $y$ & Ciénaga & Total \\
\hline & & & & \multicolumn{2}{|c|}{ Parcela } & & & cerril & & & \\
\hline $\begin{array}{l}\text { San Nicolás } \\
\text { Peralta }\end{array}$ & $10-X-1929$ & $17-X-1929$ & 631 & 66 & 113 & 55 & 27 & 776 & & & 858 \\
\hline Ampliación & 29-IX-1937 & 8-IX-1939 & & & & 56 & & & & 153 & 209 \\
\hline $\begin{array}{l}\text { San José del } \\
\text { Ilanito }\end{array}$ & 29-IX-1937 & 29-III-1946 & 171 & 13 & 37 & & & 204 & & & \\
\hline Amomolulco & $29-X-1937$ & 12-III-1951 & 307 & 7 & 23 & 32 & & & & 88 & 120 \\
\hline $\begin{array}{l}\text { San Antonio } \\
\text { de los } \\
\text { Llanitos } \\
\end{array}$ & 22-IX-1937 & 31-III-1951 & & & & 76 & & & & 206 & 282 \\
\hline Total & & & 1109 & 86 & 173 & 219 & 27 & 980 & & 447 & 1,497 \\
\hline
\end{tabular}

Fuente: elaboración con base en el GEM (1969). 
La distancia de los sitios de habitación de los propietarios y las tierras cenagosas gestaron irregularidades en los derechos de posesión, litigio por límites y aprovechamiento desordenado. Los ejidatarios con parcela se ocupaban setenta y cinco días al año en la agricultura y doscientos noventa peones cultivaban maíz con rendimientos de 500 a 700 kilogramos por hectárea; al ocuparse como como peones o cuando emigraban a Estados Unidos, las tierras quedaban al cuidado de la familia.

En los años cuarenta, la extracción y el trasvase del agua se debió a la exigencia del modelo de sustitución de importaciones y a la consecuente urbanización e industrialización, y al entramado de relaciones de poder que se tejieron alrededor del usoapropiación del recurso hídrico de la cuenca alta del río Lerma (Ibarra, 2010). La apropiación de los recursos hídricos acabó con una organización económica-social y cultura ancestral; los pobladores empezaron a emigrar a las zonas urbanas en busca de trabajo para subsistir (Albores, 1995).

La transformación del modo de vida lacustre estuvo aparejada a la irremediable pérdida de los recursos naturales; al aprendizaje de formas de vida urbana; a la inclusión en nuevas actividades, nuevos empleos y horarios de trabajo; al abandono de la vida cotidiana al aire libre y de las formas de organización social donde las familias generaban sus ingresos: pesca, caza, recolección y comercio de los productos (González y Velasco, 2015: 83,139).

El proceso tecnológico del sistema hidráulico del alto Lerma para captar el agua de los manantiales y mantos freáticos por medio de la perforación de pozos trascendió los derechos de los propietarios de los recursos hídricos, de los pueblos indígenas, de los ejidatarios y comuneros, lo cual generó traslocación de los beneficios y los costos sociales; es decir, el agua pasó de recurso básico para la reproducción social a insumo de la producción industrial y urbana.

Las obras hidráulicas interrumpieron la ruralidad y desarticularon el sistema lacustre; los efectos se manifestaron en la canalización de los manantiales, sobreexplotación del agua subterránea, reducción y desecación de la superficie lacustre, formación de planicies inundables que a la postre se utilizarían para uso urbano e industrial, cultivo, pastoreo y vías de comunicación (figura 1).

En los años sesenta y setenta la sedienta Ciudad de México llevó a la implantación del sistema hidráulico del río Cutzamala; fue hasta los años ochenta, en su primera etapa, aportaba 4.000 1/s de agua extraída de la presa Villa Victoria, la operación afectó zonas de producción y abastecimiento de agua de comunidades indígenas Mazahua.

El escenario de vulnerabilidad hídrica sostiene el abatimiento de la provisión de agua del sistema hidráulico alto Lerma; aportaba $14 \mathrm{~m} 3 / \mathrm{s}$ y en la actualidad aporta $4 \mathrm{~m} 3 / \mathrm{s}$ y el sistema Cutzamala $9 \mathrm{~m} 3 / \mathrm{s}$; se estima que el agua de transvase se reducirá $50 \%$ y más (SACMEX, 2016; Ávila, 2017). 
Figura 1. Impactos del proyecto hidráulico Alto Lerma

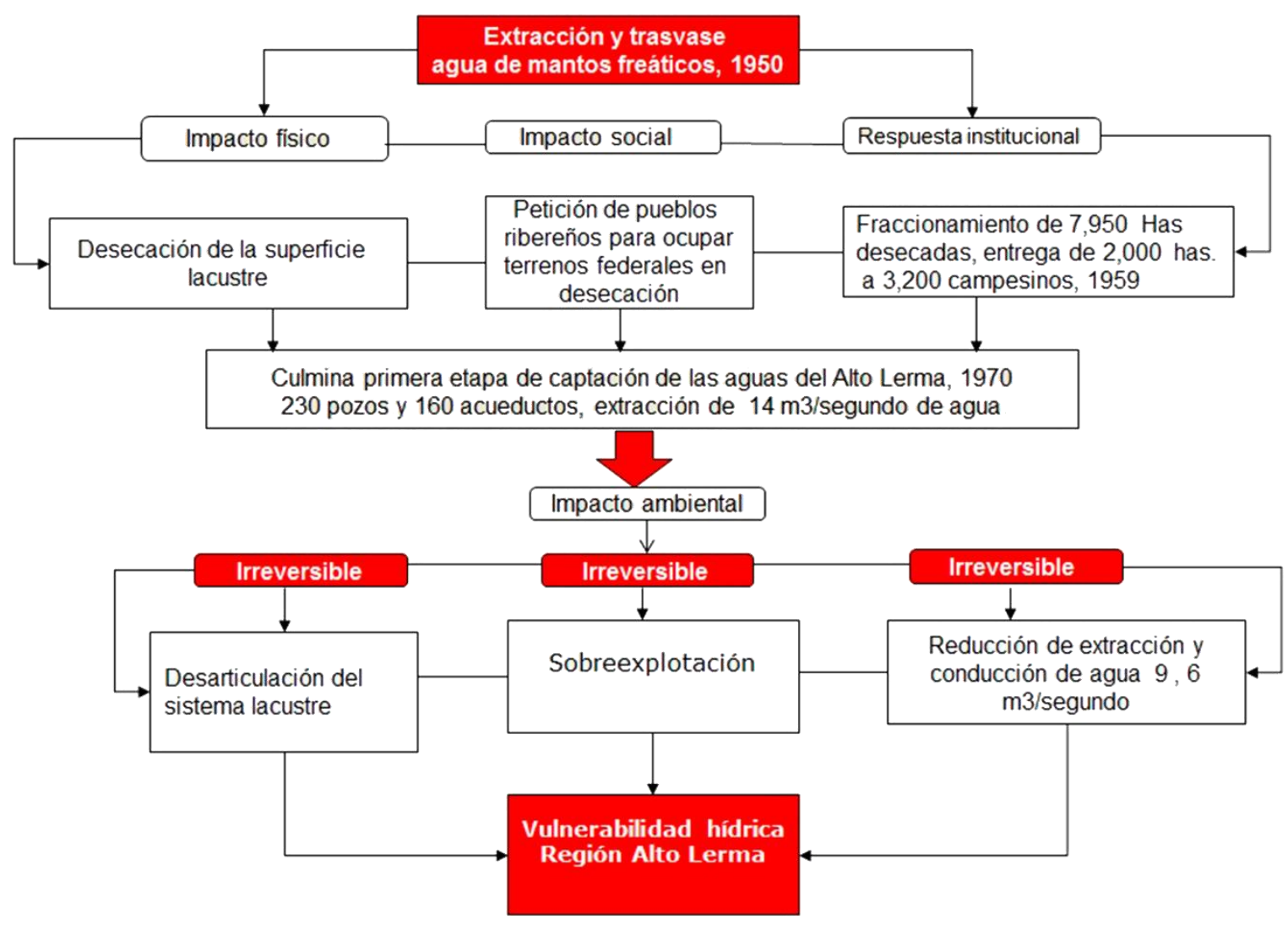

Fuente: elaboración con base en Romero (1974), Albores (1995) y Sugiura (1998).

\section{Entorno regional de los conflictos ambientales}

En la región del alto Lerma, la cadena montañosa Monte alto-las cruces forma el límite natural de las cuencas alta del río Lerma y la de México; el rasgo sobresaliente es el bosque templado y el sustrato intercalado por derrames lávicos y depósitos con distinto grado de consolidación que proveen recursos hídricos. La topografía escalonada inicia en un rango de altitud de 2,800-3,410 msnsm, y pendiente de 30 y más; el drenaje dendrítico de corrientes superficiales intermitentes $y$ algunas permanentes forman barrancos característicos de las zonas de erosión (INE, 2003: 16) (figura 2).

La conservación y el aprovechamiento del bosque caracterizan la controversia entre la propiedad patrimonial que está en manos de las comunidades indígenas y el valor ecológico que, en 1980, le confirió la categoría de Parque Estatal Otomí-Mexica en una superficie de 105,844.13 hectáreas, distribuidas en dieciocho municipios; entre ellos, Lerma, Santuario del Agua, 2006, Patrimonio Ecológico del Estado de México, 2007 (CEPANAF, 2019). 
Figura 2. Vertiente poniente de la sierra de las Cruces, Toluca-Lerma

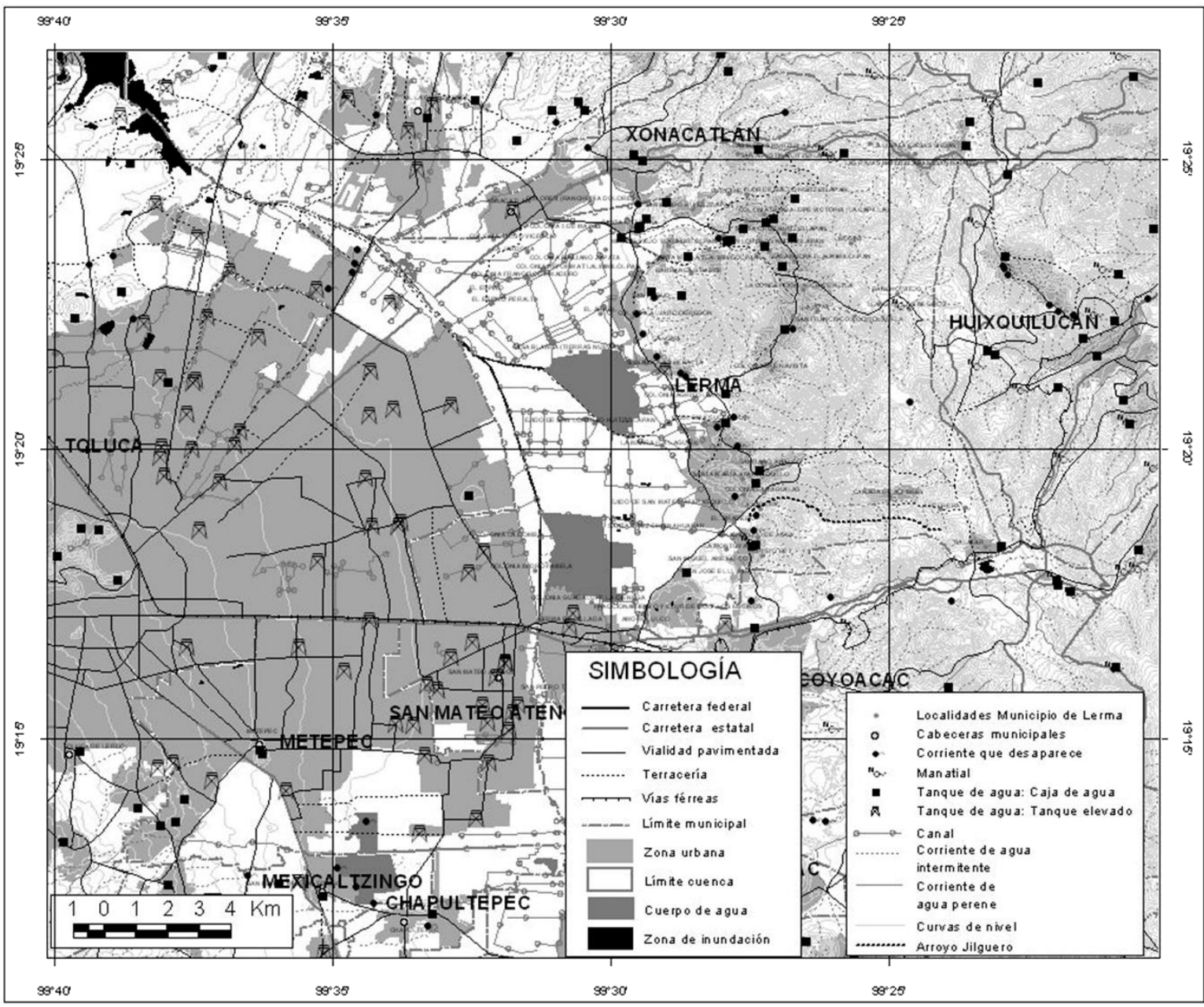

Fuente: elaboración con base en INEGI (2010).

En la vertiente poniente de la sierra de las Cruces, el bosque de oyamel, pino y encino ocupa $28 \%$ de la superficie del municipio de Lerma; la vegetación hidrófita, principalmente Tule crece en las Ciénegas de Chignahuapan y Chimaliapan (cuadro 2).

La infiltración del agua nutre los manantiales El Calvario, Amomolulco, Alta Empresa, Ameyalco en Lerma y el acuífero del valle de Toluca. El uso de los manantiales confronta los intereses de los comités comunitarios que regulan la distribución del agua local y las funciones de Organismo Público Descentralizado de Agua Potable, Alcantarillado y Saneamiento (OPDAPAS). De acuerdo con Cadena \& Salgado (2017), los comités de agua adquieren diversidad de configuraciones que surgen en espacios de conflicto de intereses, y se caracterizan por el hermetismo, la desconfianza, la falta de respeto a la autoridad y poca capacidad de negociación, lo que pone en riesgo a la organización. 
AÑO 22, 2020-1 ENERO-JUNIO E-ISSN 2594-102X PÁGS.5-33 LP:

\begin{tabular}{lll}
\multicolumn{4}{l}{ Cuadro 2. Cubiertas forestales del municipio de Lerma } \\
\begin{tabular}{lll}
\hline Cubierta forestal & Hectáreas & $\%$ \\
\hline Bosque de oyamel & 3,008 & 28.6 \\
\hline Bosque de oyamel-vs & 143 & 1.4 \\
\hline Bosque de pino & 1,169 & 11.1 \\
\hline Bosque de pino-vs & 190 & 1.8 \\
\hline Bosque de encino & 1,085 & 10.3 \\
\hline Bosque de encino- vs & 719 & 6.8 \\
\hline Bosque encino-pino & 221 & 2.1 \\
\hline Pastizal & 1,338 & 12.7 \\
\hline Vegetación hidrófita & 2,461 & 23.4 \\
\hline Degradación & 178 & 1.7 \\
\hline Total & 1,0512 & 100.0 \\
\hline
\end{tabular}
\end{tabular}

Fuente: elaboración con base en GEM (2010).

La fuerza política se manifiesta en las iniciativas para modificar los ordenamientos nacionales. La propuesta de Ley General de Aguas, publicada en la Gaceta Parlamentaria del 5 de marzo de 2015 (No. 4228-II), busca colocar el agua como un objeto mercantil sujeto a las leyes de la oferta y la demanda, contraviniendo la carta magna que garantiza el agua como un derecho humano (Hatch et al., 2017: 30), lo que vislumbra al sector privado en la conducción del agua de las zonas de producción a las zonas de consumo; la crítica llevó a postergar la propuesta en espera de retomarla por medio de la consulta ciudadana.

El movimiento social por la defensa del Bosque de Agua y las Ciénegas de Lerma se sustenta en argumentos conservacionistas y en la soberanía de los pueblos indígenas para decidir sobre el destino de los recursos naturales que son de su propiedad. Estas motivaciones dieron forma al Frente de Pueblos Indígenas en Defensa de la Madre Tierra; las comunidades se opusieron a la construcción de la autopista Toluca-Naucalpan que comunicaría las ciudades de Toluca y México (GEM, 2003) y a la vialidad Toluca-tres María-Cuernavaca que afectarían el bosque de agua, la Ciénega de Chignahuapan y al corredor Biológico Chichinautzin.

Después de algunos años de conflicto y clausuras parciales, la vialidad TolucaNaucalpan que atraviesa el bosque de agua o Parque Estatal Otomí-Mexica está en operación, y la vialidad Toluca-tres María-Cuernavaca está suspendida debido a que afecta un área protegida federal: el Área de Protección de Flora y Fauna Ciénegas de Lerma. La belleza escénica y la cercanía a las zonas urbanas dota de alto valor a las tierras forestales; los intereses económicos mueven su poder para construir obras y servicios cambiando la regulación del suelo (Cortés, 2014: 71). 
Los lomeríos y el pie de monte con altitudes de 2500-2800 msnm y pendiente de $10^{\circ}-25^{\circ}$ exhiben crecimientos irregulares en los asentamientos de origen otomí ${ }^{1}$ y densificación de las localidades rurales-urbanas. ${ }^{2}$

En la planicie con pendiente de $0^{\circ}$ a $6^{\circ}$ destaca la ciudad de Toluca; los límites urbanos se expanden hacia el oriente en tierras ejidales del municipio de Lerma; dominan los suelos arcillosos, ricos en materia orgánica y drenaje lento, formación de asentamientos suburbanos y desarrollos inmobiliarios; en las inmediaciones de las Ciénegas de Chignahuapan y Chimaliapan predominan asentamientos, industrias, tierras de cultivo y pastoreo.

\section{Legitimación del valor ecológico de las Ciénegas de Lerma}

Con el objeto de proteger uno de los pocos sitios de la República Mexicana que conserva ecosistemas de alta biodiversidad y extrema fragilidad -últimos remanentes de lo que fueron los extensos humedales del altiplano central (Patrick, 2012: 6) -, el 27 de noviembre del 2002 se decretó el Área de Protección de Flora y Fauna Ciénegas de Lerma (SEMARNAT, 2002: 4); tras esta iniciativa, el área se incorporó a la lista de humedales más importantes del planeta-Ramsar (CONAFOR, 2011; 2017) (figura 3).

El área protegida se ubica en la región neártica mexicana; cubre una extensión de 3,023 hectáreas o 1.5\% del curso alto del río Lerma. La superficie se distribuye en tres Ciénegas independientes conectadas por canales artificiales al río Lerma: Chiconahuapan o Almoloya (596-15-79 has); Chimaliapan (2081-18-63 has), Chignahuapan o Atarasquillo (346-61-28 has) comprenden la jurisdicción de los municipios de Lerma, Tianguistenco, Almoloya del Río, Capulhuac, San Mateo Atenco, Metepec y Texcalyacac (GEM, 1993).

El valor ecológico de la región se funda en su importancia como centro de refugio para aves migratorias que anualmente arriban en invierno desde Canadá, Estados Unidos y el Norte de México. En la época invernal, alberga poblaciones de aves que fluctúan entre 30,000 y 100,000, debido a que en la zona se concentran dieciocho especies de aves de interés cinegético; en 1999, la Comisión para la Cooperación Ambiental, que colabora en la conservación de la avifauna de América del Norte, la reconoció como un área importante para la conservación de aves de América del Norte (Ceballos, 2003: 3).

\footnotetext{
${ }^{1}$ Cañada de Alférez, San Francisco Xochicuautla, Santiago Analco, San Lorenzo Huitzizilapan, Zacamulpa Huitzizilapan, San Pedro Huitzizilapan, San Agustín Huitzizilapan, Colonia Adolfo López Mateos, Colonia Guadalupe Victoria, Las Mesas Huitzizilapan, Las Mesas Huitzizilapan, San Martín Las Rajas, La Unidad Huitzizilapan, Santa Cruz Huitzizilapan, Flor de Gallo Huitzizilapan, entre otras.

2 San Mateo y Santa María Atarasquillo, Metate Viejo, San Nicolás Peralta, Colonia Adolfo López Mateos, Colonia Guadalupe Victoria.
} 
Figura 3. Área de Protección de Flora y Fauna Ciénegas de Lerma

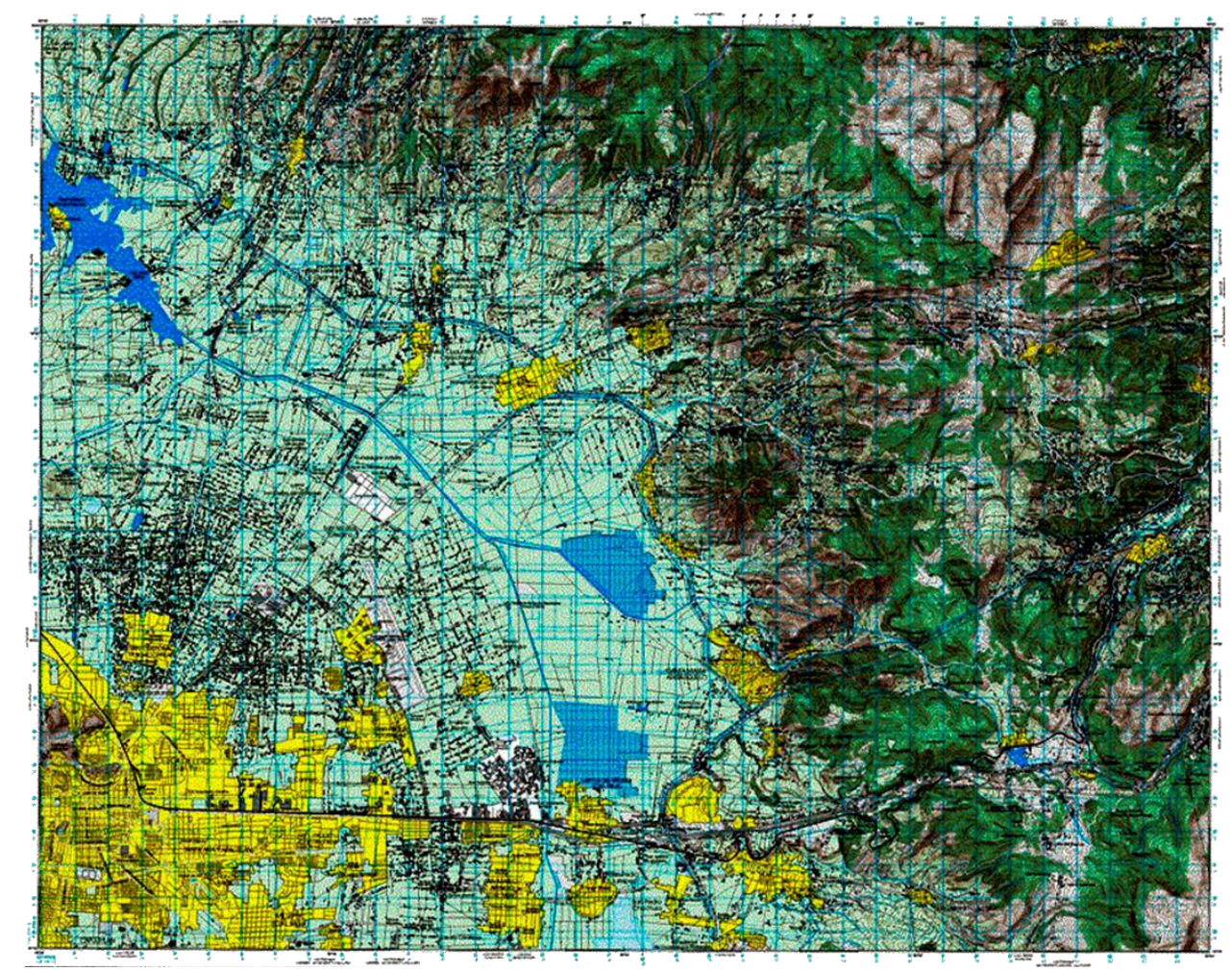

Fuente: INEGI (2010).

La categoría de protección dispone de preservación, repoblación, propagación, aclimatación, refugio, investigación, educación, difusión y aprovechamiento de los recursos naturales por parte de comunidades con derechos de usufructo (DOF, 1998: 40). La Ley General de Vida Silvestre, las normas mexicanas y los ordenamientos aplicables establecen criterios para que los propietarios gestionen autorizaciones y concesiones para desarrollar obras, actividades económicas y aprovechen la biodiversidad.

Con la finalidad de aprovechar el hábitat invernal de diecisiete especies de patos y cercetas migratorias, en 2003 se crearon diez unidades de manejo para la conservación de vida silvestre (UMAS): tres en Chiconahuapan, dos en Chimaliapan y cinco en Chignahuapan, bajo regímenes de propiedad privada, ejidal, municipal y federal. A través de las UMAS, se permite aprovechar ejemplares, partes y derivados de vida silvestre; el aprovechamiento distingue el extractivo (actividad cinegética, mascotas, ornato, artesanales, colecta científica e insumos para la industria farmacéutica, alimentaria y del vestido, entre otras) y no extractivo (investigación, exhibición, ecoturismo y educación ambiental) (DOF, 2000). 
La legitimación del valor ecológico del área de protección y las UMAS destinadas al aprovechamiento cinegético ignoran los factores de presión y los efectos negativos, resultado de las actividades antropogénicas. Los factores de presión directa que impactan la biodiversidad del ecosistema lacustre identifican los cambios de uso de suelo -cultivos y espacios urbanos- y la contaminación del agua; los efectos se manifiestan en pérdida de zonas de agua abierta y cubierta de tule, transformadas en zonas de baja inundación que favorecen una flora hidrófita de menor talla y adaptada a los disturbios, malezas terrestre y acuática que evidencian deterioro de los hábitats. Aun cuando las Ciénegas poseen una diversidad vegetal significativa, estos sistemas están sujetos a cambios negativos drásticos e irreversibles si las condiciones de perturbación, contaminación y disminución del nivel de agua no se revierten (Zepeda et al., 2012a: 48; Zepeda et al., 2012b: 23).

\section{Fuentes de aguas residuales y calidad del agua en las Ciénegas de Lerma}

En el Estado de México se registran cuatrocientos cuarenta y cuatro puntos de descarga de aguas residuales municipales sin tratamiento; en los municipios no aparece dato alguno (INEGI, 2017). La información de las descargas de aguas residuales industriales es dispersa o ausente, aunado a las descargas ilegales no cuantificables.

El crecimiento demográfico y las actividades económicas se erigen como factores de presión indirecta que crean las externalidades ambientales; en este caso, la contaminación por la descarga de aguas residuales. En el conjunto de municipios que forman el área de influencia del área protegida reside más de medio millón de habitantes; en 2010, 556,481 habitantes y, para 2018, aumentó a 637,515; Metepec y Lerma concentran $65 \%$ de esta población (figura 4).

Figura 4. Población total. Área de influencia de las Ciénegas de Lerma
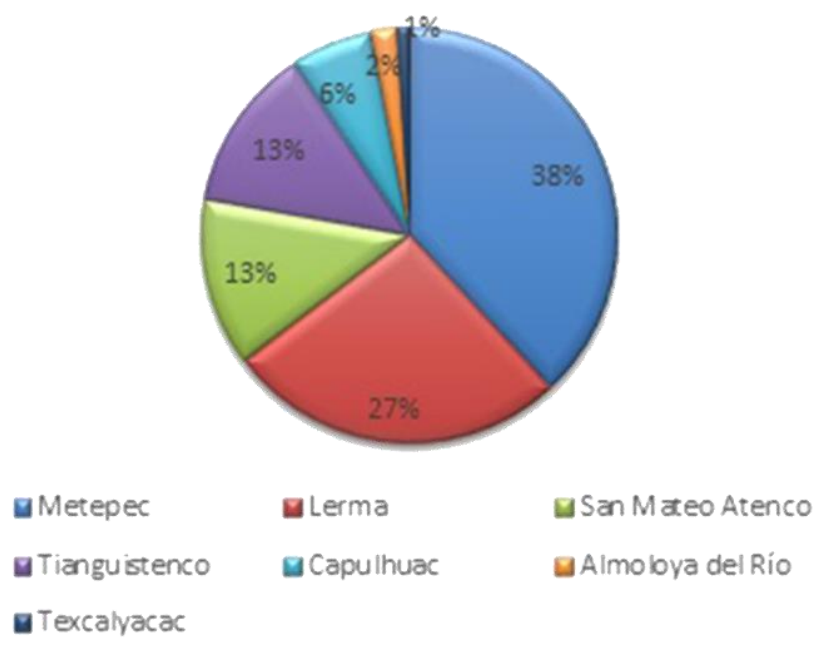

Fuente: elaboración con base en CONAPO (2016). 
El área también concentra 3,900 industrias; la especialización sugiere los focos de contaminación fuerte; el municipio de Lerma cuenta con siete parques industriales; prevalecen las ramas textil, automotriz, metal mecánica y alimentos. En Metepec, los talleres artesanales; en San Mateo Atenco, la manufactura de calzado; en Santiago Tianguistenco, la industria automotriz y maquila de ropa; y, en Almoloya, la maquila de ropa. En los municipios en donde se maquila ropa, se genera pedacería de telas sintéticas, tinturas y solventes que se depositan en los cuerpos de agua; la contaminación se observó en la coloración multicolor y en el olor de agua estancada en la Ciénegas de Chiconahuapan o Almoloya y en Chimaliapan o Lerma (figura 5).

Figura 5. Área de influencia Ciénega de Chignahuapan. Unidades manufactureras, 2017

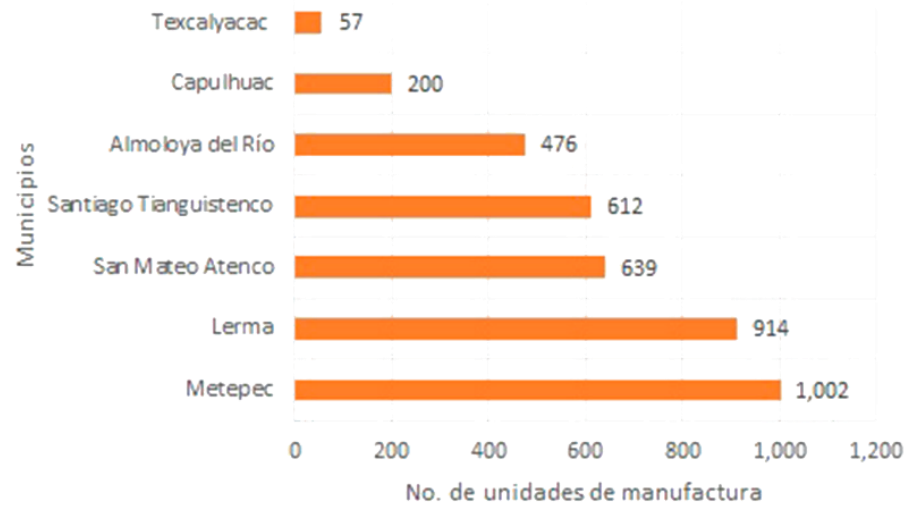

Fuente: elaboración con base en INEGI (2017).

En Metepec el volumen anual de aguas negras por drenaje es de cerca de 13'438,802.80 litros; sólo se trata 2\%; aproximadamente, 279 mil 471 litros por segundo. El agua residual sin tratamiento se descarga en el río San Gaspar, arroyo Agua Bendita (El Arenal), canal Insurgentes) y canal San Isidro (H. Ayuntamiento de Metepec, 2016: 118119). En Lerma, el volumen de aguas residuales asciende a 32,962 $\mathrm{m}^{3} /$ día; sólo se tratan 7,553 m³ / día o 22\% (H. Ayuntamiento de. Lerma, 2013: 76, 93). El problema común es la carencia y la obsolescencia de las redes para conducción y desalojo de agua pluvial, así como la carencia o poca capacidad de las plantas municipales de tratamiento de aguas residuales; la mayor parte del agua residual con autorización de la Comisión Nacional del Agua (CONAGUA) se vierte en los arroyos, drenes agrícolas y colectores a cielo abierto sin tratamiento.

Los parámetros de la calidad del agua en el periodo 2012-2018 indican que en la laguna de Almoloya del Río (polígono 1), en la Ciénega de Lerma o Chimaliapan (polígono 2) y en la Ciénega de Chignahuapan o Atarasquillo (polígono 3) la contaminación es progresiva (cuadro 3). 
María Estela Orozco-Hernández, Gratia Deii Flores-Salgado e Ilse Ibeth Díaz-Ramírez: Externalidades ambientales y resiliencia lacustre...

Cuadro 3. Calidad del agua, Ciénegas de Lerma, 2012-2018

\begin{tabular}{|c|c|c|c|c|}
\hline \multicolumn{5}{|c|}{ Chiconahuapan, Almoloya del Río } \\
\hline Fecha monitoreo & $\begin{array}{c}\mathrm{SST} \\
\mathrm{mg} / \mathrm{L}\end{array}$ & $\begin{array}{c}\text { DBO_TOT } \\
\mathrm{mg} / \mathrm{L}\end{array}$ & $\begin{array}{c}\text { DQO_TOT } \\
\mathrm{mg} / \mathrm{L}\end{array}$ & $\begin{array}{c}\text { COLI_FEC } \\
\text { NMP } / 100 \mathrm{ml}\end{array}$ \\
\hline $19 / 11 / 2012$ & 100 & 38.1 & 131.07 & $<3$ \\
\hline $15 / 05 / 2013$ & 38 & 34.3 & 434.9 & 4 \\
\hline $19 / 09 / 2013$ & $<10$ & 2.9 & 212.46 & 1100 \\
\hline $23 / 04 / 2014$ & 90 & 46.9 & 111.12 & 4600 \\
\hline $07 / 10 / 2014$ & 132 & 11.3 & 241.7 & $>24000$ \\
\hline $08 / 05 / 2015$ & 52 & 2.83 & 88.86 & $>24000$ \\
\hline 03/09/2015 & 260 & 18.6 & 216.78 & 430 \\
\hline $19 / 03 / 2016$ & 94 & 24 & 28.11 & $>24000$ \\
\hline $10 / 08 / 2016$ & 70 & 24.3 & 124.81 & $>24196$ \\
\hline $23 / 03 / 2017$ & 42 & 8.65 & 169.5 & 410 \\
\hline $29 / 09 / 2017$ & 36.67 & 24.97 & 88.67 & 24196 \\
\hline $29 / 04 / 2018$ & 120 & 21.76 & 230.17 & 3410 \\
\hline $18 / 07 / 2018$ & 50 & 40.33 & 142.79 & 241960 \\
\hline $04 / 12 / 2018$ & 29 & 14.8 & 117.57 & 1523 \\
\hline $19 / 11 / 2012$ & 34 & 38.7 & 82.56 & $<3$ \\
\hline $15 / 05 / 2013$ & 56 & 21.5 & 277.2 & 460 \\
\hline $20 / 09 / 2013$ & 120 & 16.8 & 291.15 & 1100 \\
\hline $23 / 04 / 2014$ & 50 & 22.7 & 227.11 & 90 \\
\hline $07 / 10 / 2014$ & 76 & 4.9 & 191.13 & 930 \\
\hline $08 / 05 / 2015$ & 250 & 69.29 & 589.58 & 150 \\
\hline $03 / 09 / 2015$ & 120 & 16.6 & 234.51 & 43 \\
\hline $19 / 03 / 2016$ & 420 & 41 & 283.68 & 150 \\
\hline $10 / 08 / 2016$ & 48 & 13.5 & 174.34 & 24196 \\
\hline $23 / 03 / 2017$ & 72 & $<2$ & 260.91 & 2247 \\
\hline $29 / 09 / 2017$ & 36.54 & 9.91 & 123.44 & 173 \\
\hline $29 / 04 / 2018$ & 114.81 & 11.01 & 255 & $<100$ \\
\hline $18 / 07 / 2018$ & 72 & 41.03 & 328.09 & 200 \\
\hline $04 / 12 / 2018$ & 56.92 & $<2$ & 106.86 & $>24196$ \\
\hline \multicolumn{5}{|c|}{ Chimaliapan, Lerma } \\
\hline $26 / 11 / 2012$ & 14 & 13.2 & 72.86 & $<3$ \\
\hline $19 / 09 / 2013$ & 12 & $<2$ & 33.26 & 150 \\
\hline $25 / 04 / 2014$ & $<10$ & 3 & 68.94 & $<3$ \\
\hline $08 / 10 / 2014$ & $<10$ & 2 & 140.03 & 4 \\
\hline $13 / 05 / 2015$ & 12 & $<2$ & 141.04 & 430 \\
\hline $04 / 09 / 2015$ & 38 & 3.6 & 56.81 & 150 \\
\hline \multicolumn{5}{|c|}{ Chignahuapan, Atarasquillo } \\
\hline $28 / 11 / 2012$ & $<10$ & 34.2 & 59.6 & $<3$ \\
\hline $06 / 04 / 2013$ & 46 & 12.9 & 133.2 & 40.0 \\
\hline $10 / 08 / 2013$ & $<10$ & 17.1 & 67.6 & 150.0 \\
\hline $21 / 02 / 2014$ & $<10$ & 4.8 & 96.2 & $<3$ \\
\hline $01 / 08 / 2014$ & 52 & 2.9 & 65.2 & 40.0 \\
\hline $14 / 04 / 2015$ & 20 & 5.6 & 97.5 & 230.0 \\
\hline $30 / 07 / 2015$ & $<10$ & 2.5 & 51.1 & 150.0 \\
\hline $10 / 05 / 2016$ & ND & 222.1 & 419.5 & 430.0 \\
\hline $17 / 08 / 2016$ & 16 & 30.2 & 38.2 & 110.0 \\
\hline $28 / 09 / 2017$ & 16 & 11.2 & 33.0 & $<30$ \\
\hline $24 / 03 / 2018$ & 48 & 45.2 & 273.7 & 90.0 \\
\hline $14 / 11 / 2018$ & 92 & 20.7 & 59.2 & $<30$ \\
\hline
\end{tabular}

\begin{tabular}{ll}
\hline & Excelente \\
\hline Buena calidad \\
\hline Aceptable \\
\hline Contaminada \\
\hline Fuertemente contaminada \\
\hline
\end{tabular}


La concentración de sólidos suspendidos (SS) determina una calidad del agua superficial de excelente a buena en las Ciénegas de Chimaliapan y Chignahuapan, lo cual favorece la conservación de las comunidades acuáticas y riego agrícola irrestricto. En la Ciénega de Chiconahuapan, Almoloya del rio, califican el agua superficial de buena calidad a aceptable.

Las variaciones de la demanda bioquímica de oxígeno (DBO) se relacionan con el aumento o la disminución de la materia orgánica en el agua superficial; este parámetro diferencia la calidad aceptable a contaminada en las Ciénegas de Chiconahuapan y Chignahuapan; contrasta con la calidad del agua excelente en Chimaliapan.

En Chimaliapan y Chignahuapan los valores de coliformes y toxicidad superficial y fondo <1 califican el agua excelente y no tóxica. En Chiconahuapan o Almoloya, la contaminación por coliformes fecales es aguda. La demanda química de oxígeno (DQO) indica altas concentraciones de materia orgánica; entre otros componentes, proteínas, grasas y productos químicos que determinan las clases de agua de contaminada a fuertemente contaminada. Desde este indicador, la laguna de Almoloya del Río es la más contaminada, seguida por Chignahuapan y Chimaliapan.

Las descargas municipales e industriales afectan severamente la calidad del agua; contribuyen a la eutrofización de los cuerpos de agua superficiales por aporte de materia orgánica en descomposición; son peligrosas para la salud humana por los agentes tóxicos e infecciosos que contienen; especialmente, las aguas crudas industriales generan contaminación térmica que abate el oxígeno disuelto (SEMARNAT, 2018).

\section{Entorno de la Ciénega de Chignahuapan, Atarasquillo}

La Ciénega de Chignahuapan, Atarasquillo, conforma el tercer polígono del Área Natural Protegida de Flora y Fauna Ciénegas de Lerma. El cuerpo lacustre se localiza a los $19^{\circ} 20^{\prime}$ $24^{\prime \prime}$ y $19^{\circ} 21^{\prime} 28^{\prime \prime}$ de latitud norte y $99^{\circ} 29^{\prime} 26^{\prime \prime}$ y $99^{\circ} 31^{\prime} 08^{\prime \prime}$ de longitud oeste. El encerramiento data de la desecación del lago de Lerma y la construcción del acueducto del sistema Cutzamala, en seis décadas la superficie se redujo de 1,613 a 346-61-28 hectáreas; actualmente, ocupa el 11\% del Área de Protección de Flora y Fauna Ciénegas de Lerma; regula la infiltración del acuífero de Toluca y las inundaciones. El cuerpo lacustre se delimita al este por la sierra de las cruces y localidades con una población menor a 2,500 habitantes; al oeste, por la mancha urbana de la ciudad de Toluca, el canal del río Lerma y el ducto del sistema Cutzamala; al norte, por tierras de cultivo; y, al sur, por vialidades que comunican Toluca y la Ciudad de México (figura 6). 
Figura 6. Confinamiento de la Ciénega de Chignahuapan, Atarasquillo

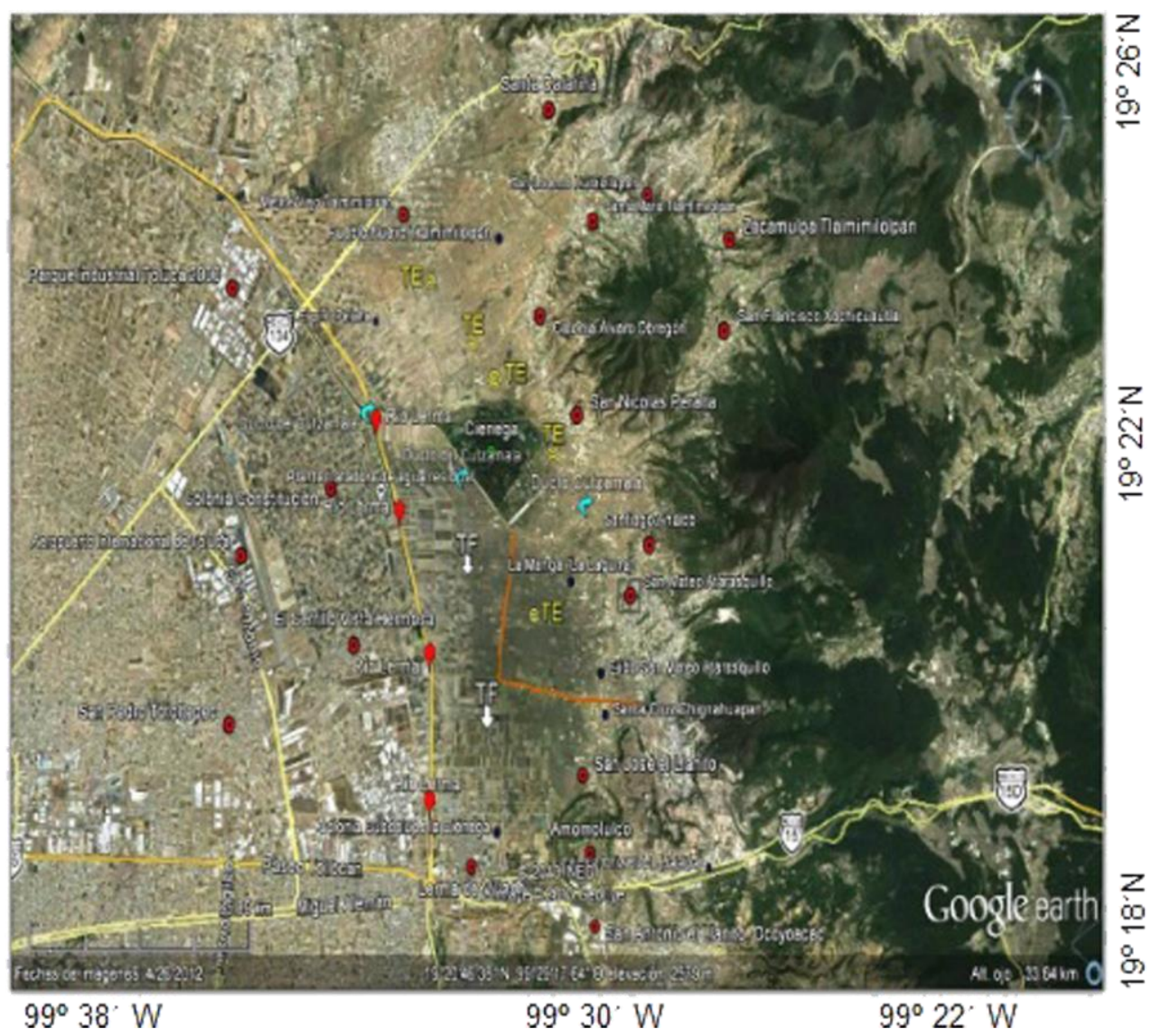

Fuente: elaboración con base en Google earth (2013).

El cuerpo lacustre recibe agua de la infiltración de la sierra de las cruces y la escorrentía de los conos volcánicos cercanos; en el área se distribuyen veintinueve acueductos y ochenta y seis canales a cielo abierto. Debido la destrucción de la margen derecha, el arroyo el Jilguero, convertido en canal de aguas residuales, vierte sus aguas en la Ciénega.

En el borde se ubican localidades de origen agrario (San Nicolás Peralta, Amomolulco, San José el Llanito y el Ejido de San Mateo Atarasquillo) y asentamientos irregulares en terrenos desecados: Colonia Guadalupe la Ciénega, Santa Cruz Chignahuapan y la Manga (La Laguna). La tasa de crecimiento ratifica incremento de la población debido a la inmigración de población que nació en otra entidad y contrasta con la disminuida población indígena, lo cual representa el 1\% de la población total (cuadro 4). 
AÑO 22, 2020-1 ENERO-JUNIO E-ISSN 2594-102X PÁGS. 5-33 I:LiE:

Cuadro 4. Tasas de crecimiento medio anual de la población, 2000-2010

\begin{tabular}{|c|c|c|c|}
\hline Localidades & $\begin{array}{l}\text { Población total } \\
2000\end{array}$ & $\begin{array}{l}\text { Población total } \\
2010\end{array}$ & $\begin{array}{l}\text { Tasa de crecimiento anual } \\
2000-2010\end{array}$ \\
\hline San Nicolás Peralta & 3,672 & 4,573 & 2.2 \\
\hline Amomolulco & 487 & 832 & 5.5 \\
\hline San José el Llanito & 1,085 & 1,333 & 2.0 \\
\hline Ejido de San Mateo Atarasquillo & 301 & 641 & 7.9 \\
\hline Subtotal & 5,545 & 7,379 & 2.9 \\
\hline Colonia Guadalupe la Ciénega & 395 & 1002 & 9.8 \\
\hline Santa Cruz Chignahuapan & 418 & 690 & 5.1 \\
\hline La manga (la laguna) & 366 & 768 & 7.7 \\
\hline Subtotal & 1,179 & 2,460 & 7.6 \\
\hline Total & 6,724 & 9,839 & 3.9 \\
\hline
\end{tabular}

Fuente: elaboración con base en INEGI (2000 y 2010).

La sub urbanización tiene sus causas en los bajos ingresos de la población, el precio accesible de los terrenos y el trato directo comprador y vendedor. La marginación se aprecia en las viviendas habitadas, de las cuales el 90\% tiene piso de tierra (cuadro 5).

Cuadro 5. Población no originaria de la entidad y viviendas con piso de tierra

\begin{tabular}{|c|c|c|c|c|c|c|c|}
\hline Localidades & $\begin{array}{l}\text { Población } \\
\text { nacida en la } \\
\text { entidad, } 2010\end{array}$ & $\%$ & $\begin{array}{l}\text { Población no } \\
\text { nacida en la } \\
\text { entidad, } 2010\end{array}$ & $\%$ & $\begin{array}{l}\text { Viviendas } \\
\text { habitadas }\end{array}$ & $\begin{array}{c}\text { Viviendas } \\
\text { piso de } \\
\text { tierra }\end{array}$ & $\%$ \\
\hline San Nicolás Peralta & 4252 & 93 & 270 & 6 & 1083 & 1016 & 94 \\
\hline Amomolulco & 681 & 82 & 105 & 13 & 199 & 189 & 95 \\
\hline San José el Llanito & 1049 & 79 & 233 & 17 & 320 & 310 & 97 \\
\hline \multicolumn{8}{|l|}{ Ejido de San Mateo } \\
\hline Atarasquillo & 537 & 84 & 97 & 15 & 153 & 141 & 92 \\
\hline Subtotal & 6519 & 88 & 705 & 10 & 1755 & 1656 & 94 \\
\hline Colonia Guadalupe la Ciénega & 666 & 66 & 333 & 33 & 225 & 213 & 95 \\
\hline Santa Cruz Chignahuapan & 511 & 74 & 155 & 22 & 170 & 166 & 98 \\
\hline La manga (la laguna) & 688 & 90 & 47 & 6 & 180 & 171 & 95 \\
\hline Subtotal & 1865 & 76 & 535 & 22 & 575 & 550 & 96 \\
\hline Total & 8384 & 85 & 1240 & 13 & 2330 & 2206 & 95 \\
\hline
\end{tabular}

Fuente: elaboración con base en INEGI (2000 y 2010).

Los suelos presentan restricciones para los cultivos; eventualmente, se utilizan para pastoreo de ganado; el uso alternativo es urbano con susceptibilidad al hundimiento e inundación, aunado al vertido de aguas residuales conducidas por colectores en mal estado. 
En los asentamientos de origen agrario, 6\% de la población se empleó en el sector primario; en el ejido de San Mateo Atarasquillo, la proporción se incrementó a 16\%. En los asentamientos irregulares, la población que trabajó en el sector primario representó 17\% del total; hubo mayor participación de los asentamientos irregulares de Santa Cruz Chignahuapan y La Manga, 30\% y 13\%, respectivamente (figura 7).

Figura 7. Localidades de origen agrario ocupación de la población por sector e ingreso
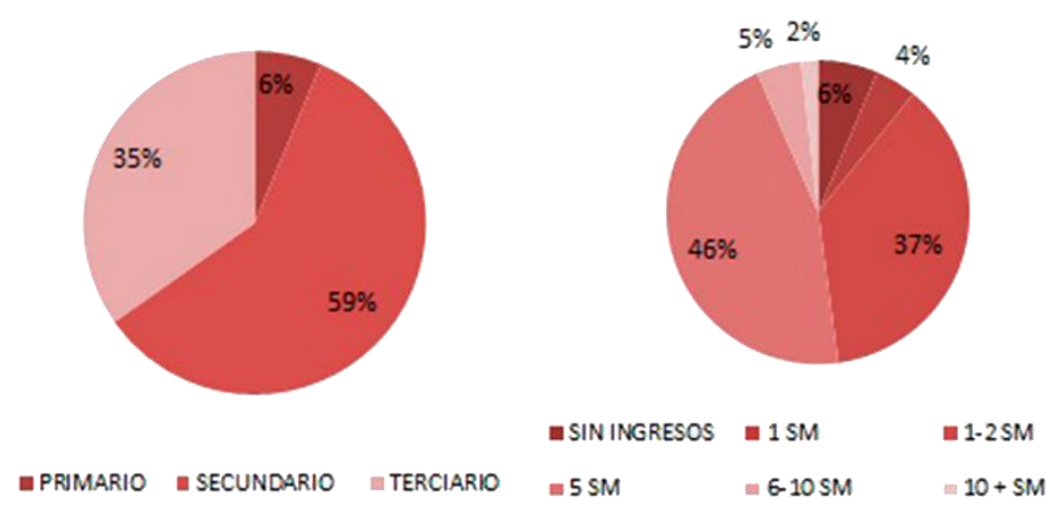

Fuente: elaboración con base en INEGI (2000).

La mayor parte de la población ocupada se emplea en los sectores secundario y terciario en el corredor industrial Lerma-Toluca; en las ciudades de Lerma de Villada y Toluca de Lerdo, el ingreso promedio va de uno a dos salarios mínimos (figura 8).

Figura 8. Asentamientos irregulares ocupación de la población por sector e ingreso
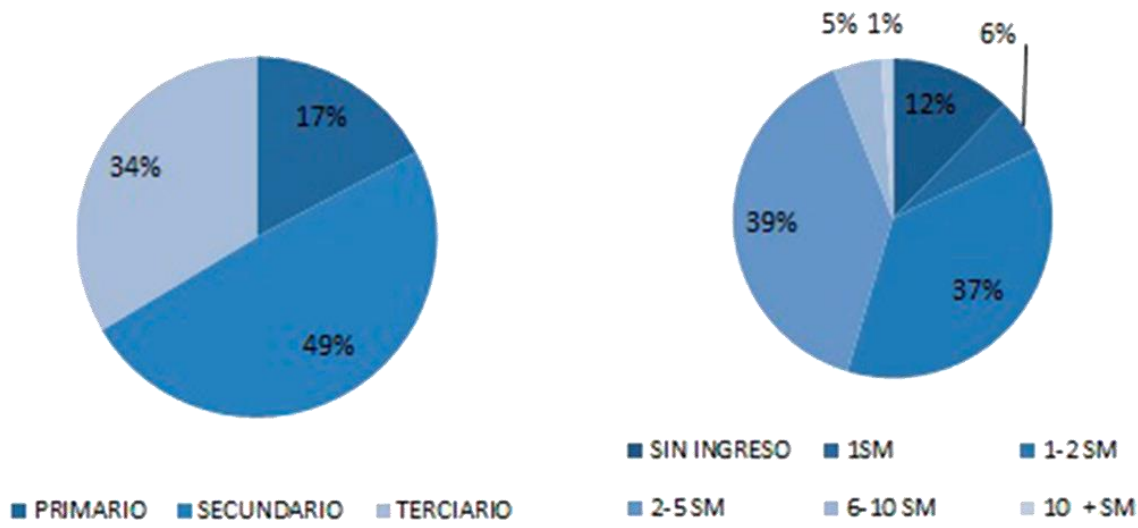

Fuente: elaboración con base en INEGI (2000). 


\section{Aprovechamiento cinegético, Ciénega de Chignahuapan, Atarasquillo}

El manejo orienta la función de hábitat de aves residentes y migratorias, la cacería deportiva, la recolección, la caza y la pesca por parte de la población local. Los ejidos de San Nicolás Peralta, Amomolulco y San Antonio de los Llanitos recibieron tierras del antiguo lago de Lerma y se benefician directamente del aprovechamiento cinegético; los ejidos de San José del Llanito y Jajalpa hicieron valer el derecho de posesionarios para gozar de esta prerrogativa. Así, la Ciénega de Chignahuapan se divide en cinco unidades de manejo para la conservación de la vida silvestre (UMAS); domina la propiedad pública (65.18\%), seguida por la social $(19.16 \%$ ) y $15.69 \%$ desincorporada por decreto; persisten los litigios por uso del cuerpo lacustre.

En las UMAS se realiza aprovechamiento extensivo; los ejemplares se encuentran en vida libre y las prácticas de conservación del hábitat se efectúan in situ. Para operar, se requiere acreditar la propiedad legítima y el plan de manejo específico, en el que se establecen metas y plazos de aprovechamiento basados en los estudios biológicos de las especies, el calendario de actividades, las medidas de manejo del hábitat, las poblaciones y los ejemplares, las medidas de contingencia y vigilancia, así como los medios y las formas de aprovechamiento, el sistema de marca para identificar ejemplares, partes y derivados aprovechados de manera sustentable (DOF, 2000: 18) (figura 9).

El manejo del agua superficial depende de las actividades que se desarrollan dentro y fuera de las unidades de aprovechamiento, pesca de carpa, recolección, caza deportiva y recorridos en lancha, actividad industrial, agricultura y pastoreo.

El manejo de la interface tierra-agua identifica que los pobladores rompen los bordos para que escape el agua hacia las zonas de cultivo, lo que acelera la desecación. Al noreste del cuerpo lacustre, en suelos producto del acarreo de sedimentos se cultiva maíz con problemas de laboreo y rendimiento bajo; además, se practica pastoreo libre de ganado vacuno y ovino; el circuito se completa con la venta de los productos en el mercado local.

Aunque se prohíben las quemas, no se sabe quién las provoca y se propagan hasta convertirse en siniestros peligrosos; la quema de tule se realiza al final de la época seca del año -febrero y mayo- y coincide con el fin de la temporada de caza. El Tular es una comunidad herbácea con altura promedio de 1 a $3 \mathrm{~m}$; habita superficies pantanosas o de agua dulce estancada, de 0.5 a $1.5 \mathrm{~m}$ de profundidad; está arraigada en el fondo del terreno y forma masas densas (Rzedowski, 1983: 343). La densidad y la altura del tule dificultan las actividades que se realizan en el periodo húmedo del año: la pesca, la recolección y la oferta de recorridos turísticos. 
Figura 9. UMAS Ciénega de Chignahuapan, Atarasquillo

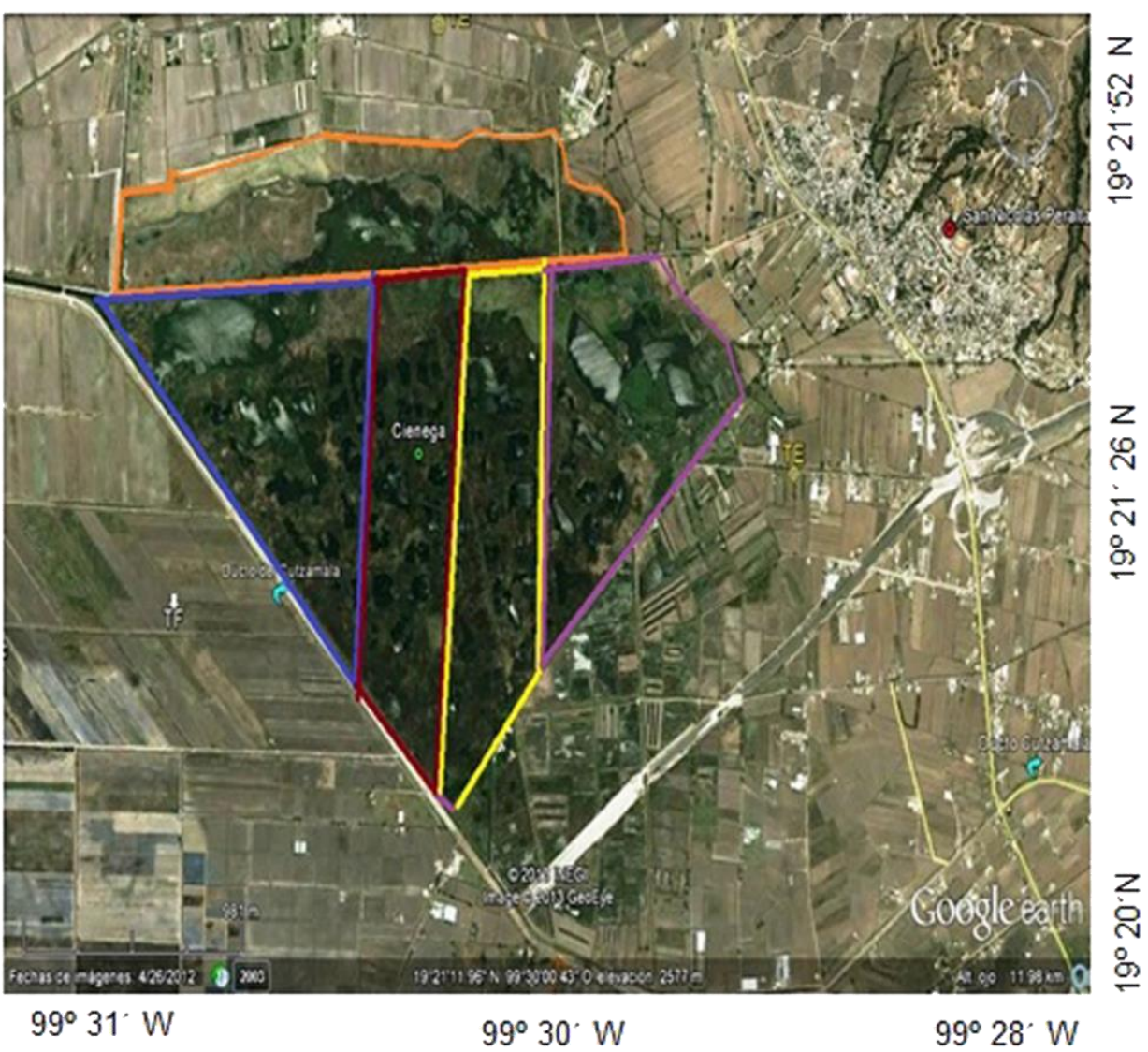

Fuente: elaboración con base en Google earth 2013 y comunicación directa. Naranja y violeta. Ejido de San Nicolás Peralta, Azul. Ejido de San Antonio el Llanito, Rojo. San José el Llanito, Amarillo. Jajalpa y Amomolulco.

En los términos de ley, la cacería de aves acuáticas (patos de especies residentes y migratorias: cercetas, gallaretas y agachonas) es una práctica deportiva controlada mediante tasas de aprovechamiento por cuotas o número de ejemplares; la temporada de cacería inicia cada año a partir del primer domingo de noviembre y termina el primer domingo de marzo.

Para cazar aves migratorias -cercetas de alas verdes y alas azules, patos trigueros, golondrinos y cucharones-, entre otros requisitos, se requiere que la Unidad de Manejo y Conservación de Vida Silvestre se registre en la Secretaría de Medio Ambiente y Recursos Naturales (SEMARNAT); es necesario que los servicios de cacería se contraten dentro de la UMA, contar con licencias de caza y portación de armas de fuego y adquirir los cintillos de cobro cinegético. 
La Ley General de Vida Silvestre sanciona la caza ilegal de especies de vida silvestre; asimismo, establece revocación de permisos y autorizaciones, inscripción a padrón de infractores, multas de hasta por 50,000 días de salario mínimo y decomiso de ejemplares e instrumentos de caza; el Código Penal Federal considera delito cuando ilícitamente se daña o da muerte a especies silvestres en alguna categoría de riesgo (PROFEPA, 2010).

La observación constató que la distancia de los lugares de residencia de los ejidatarios, con respecto a las unidades de aprovechamiento cinegético, ocasiona que las unidades de manejo no operen directamente; es decir, prefieren la renta de los derechos de usufructo a los intermediarios por un monto que cubre la temporada de caza, sensiblemente menor al cobro por un puesto de cacería.

La renta tiene una derrama económica estimada en 80 y 100 mil pesos anuales; cada puesto de caza tiene un costo que permitiría multiplicar los ingresos por toda la temporada. El arrendatario organiza las actividades por mediación de un prestador de servicios que funge como corresponsable; la cacería genera altas tasas ganancias que se concentran en grupos en conflicto y los beneficios no son equitativos. La opinión de los lugareños confirma que la cacería se realiza todo el año e intensifica en el periodo permitido algunas especies amenazadas se aprovechan en cantidades no cuantificadas.

\section{Aprovechamiento de subsistencia}

El aprovechamiento es una estrategia de adaptación general, indiscriminada y flexible que ofrece alternativas en los ciclos de baja productividad (Sugiura, 1998: 77). Los grupos de bajos ingresos aprovechan los recursos lacustres de acuerdo con el calendario estacional; en la temporada de lluvia se intensifica la pesca y la recolección, cuyas actividades se prolongan hasta otoño; en cambio, la caza de aves se práctica en la temporada seca (cuadro $6)$.

Cuadro 6. Calendario de aprovechamiento de los recursos lacustres

\begin{tabular}{|c|c|c|c|c|c|c|c|c|c|c|c|}
\hline \multirow[t]{2}{*}{ Mes } & \multicolumn{3}{|c|}{ Caza } & \multicolumn{2}{|c|}{ Pesca } & \multicolumn{6}{|c|}{ Recolección } \\
\hline & Pato & Ajolote & Rana & Carpa & $\begin{array}{l}\text { Pez } \\
\text { espejo }\end{array}$ & Acocil & Berro & Jara & $\begin{array}{l}\text { Cilantro } \\
\text { de agua }\end{array}$ & $\begin{array}{l}\text { Hongo } \\
\text { blanco }\end{array}$ & Quelite \\
\hline \multicolumn{12}{|l|}{ Enero } \\
\hline \multicolumn{12}{|l|}{ Febrero } \\
\hline \multicolumn{12}{|l|}{ Marzo } \\
\hline \multicolumn{12}{|l|}{ Abril } \\
\hline \multicolumn{12}{|l|}{ Mayo } \\
\hline \multicolumn{12}{|l|}{ Junio } \\
\hline \multicolumn{12}{|l|}{ Julio } \\
\hline \multicolumn{12}{|l|}{ Agosto } \\
\hline \multicolumn{12}{|l|}{ Septiembre } \\
\hline \multicolumn{12}{|l|}{ Octubre } \\
\hline \multicolumn{12}{|l|}{ Noviembre } \\
\hline Diciembre & & & & & & & & & & & \\
\hline
\end{tabular}

Funete: elaboración propia. 
Los ciclos de aprovechamiento identifican las figuras de recolector, pescador, cazador-pescador y cazador. Los practicantes aprendieron de abuelos, padres y amigos, pero consideran que no son actividades propicias para sus hijos (figura 10).

Figura 10. Aprovechamiento de recursos lacustres
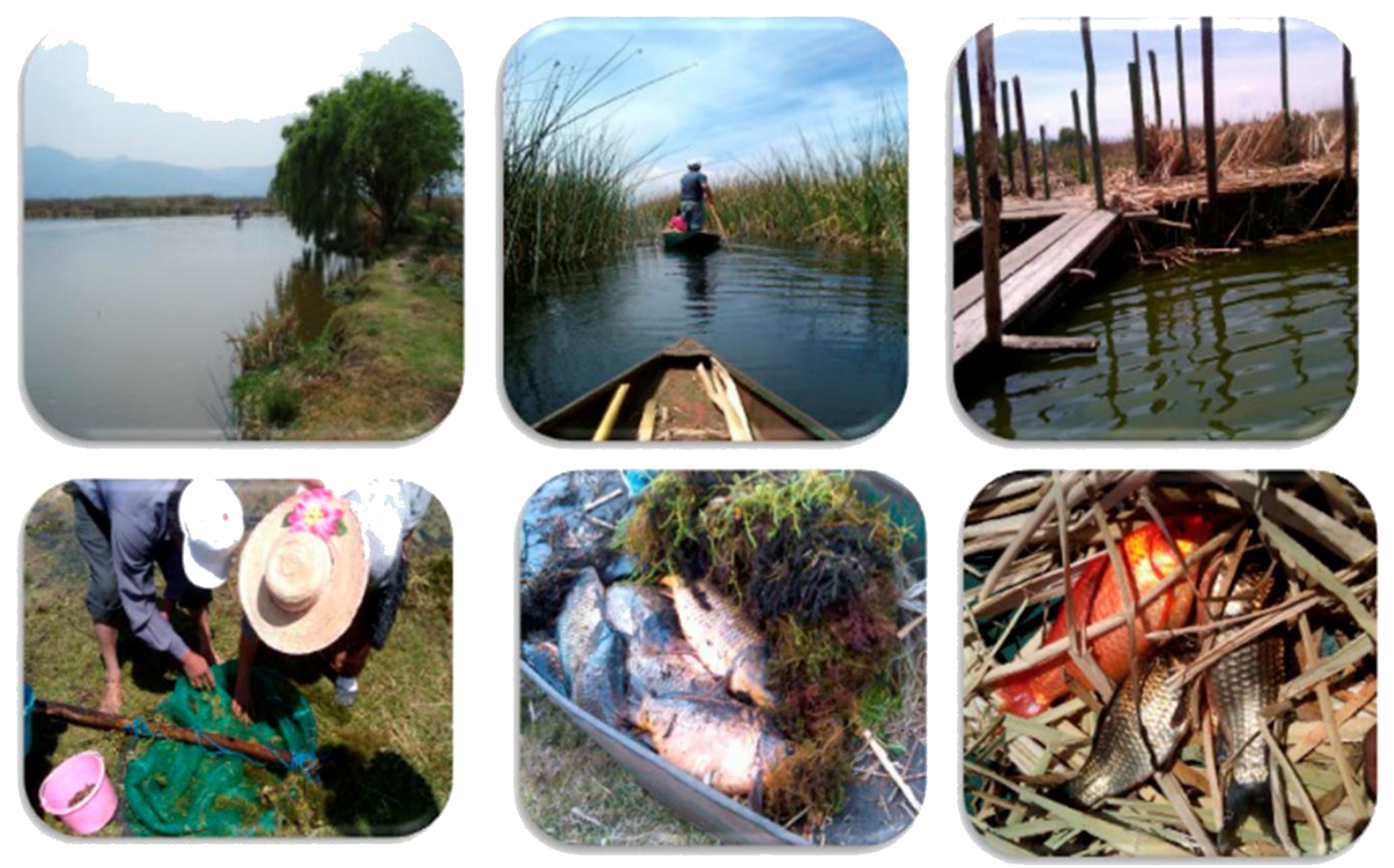

Fuente: elaboración propia.

Los recolectores tienen edad promedio de 56 años; dos de cada tres residen en localidades distantes al cuerpo lacustre y realizan la actividad en primavera y verano; escudriñan en las zanjas y extraen jara, berros, quelites, hongo blanco, acociles y ranas. El acocil se captura con red de aro (Macla); posteriormente, se separa de la vegetación acuática que lo envuelve. En la colecta de otros productos no se utiliza ningún instrumento.

La recolección se intensifica en la época de lluvia (agosto-septiembre) y al final de la temporada de caza (marzo-abril y parte de mayo); los recolectores acuden a la ciénaga una $\mathrm{o}$ dos veces por semana para desarrollar la actividad individual y complementariamente con la agricultura y comercio; los productos se consumen o venden en el mercado local. Los cazadores y pescadores, cuya edad promedio es de 45 años, cazan en invierno (noviembre y febrero); los patos silvestres que anidan en la Ciénega en este periodo provienen de Canadá y Estados Unidos. 
Los pescadores realizan la actividad dos o tres veces por semana; utilizan la canoa, una fisga de tres agujas para atrapar a los peces en aguas poco profundas y la red para áreas profundas; obtienen tres o cuatro kilos de carpa al día y la comercializan en cuarenta pesos el kilo; en marzo, abril y mayo, la pesca es de tiempo completo; los hijos no quieren aprender el oficio.

El cazador-pescador participa introduciendo personas que practican la caza deportiva; asimismo, para consumo, obtienen: gallareta, ave panadera, rana, acocil, ajolote y carpa. En las Ciénegas se reporta la especie Aztecula Sallaei (Carpa Azteca), endémica de la región lacustre, cuya variación morfológica acusa pérdida de peso y talla (Flores, 2009). Los entrevistados señalaron que a través de un proyecto productivo se introdujo carpa tilapia, cuya especie es de gran capacidad reproductiva, anida en el piso lacustre y es altamente depredadora; los efectos en la cadena trófica no han sido evaluados. La densidad de las algas no permite ver el fondo lacustre; estos organismos cumplen una función ecológica importante; producen oxígeno a través de la fotosíntesis (Robledo, 1997); la exuberancia denota que se han adaptado a deficiencia de oxígeno disuelto en el agua y no tienen uso alternativo.

\section{Discusión de resultados}

Los factores estructurales, que determinaron la configuración y el estado ecológico de las Ciénegas de Lerma, remiten a los cambios de propiedad de la tierra e institucionalización del modo de producción agrario, la implantación del modelo urbano-industrial a través del sistema hidráulico del río Lerma y la explotación de agua del subsuelo; por lo tanto, las consecuencias manifestaron la fragmentación y la desecación del sistema lacustre, así como los cambios de uso de suelo para fines agrícola, urbano e industrial.

El entorno de los conflictos ambientales confronta propósitos divergentes, como impulsar la rentabilidad de las actividades urbanas e industriales, subsanar las necesidades de grupos sociales desfavorecidos y mantener la estabilidad de los ecosistemas.

Los actores sociales racionalizan los intereses y las necesidades por medio de la apropiación y el aprovechamiento del bosque y del agua; los conflictos se materializan en la competencia de los usos de suelo y en los procesos productivos.

El bosque es objeto de conflictos arraigados en la distribución de los beneficios; por un lado, los grupos étnicos, a través de la organización, defienden el derecho a decidir el aprovechamiento del bosque y del agua, así como a recibir los beneficios de las intervenciones externas; por otro lado, los gobiernos y el sector privado en el área de reserva forestal gestionan la explotación de los manantiales, la construcción de vialidades y el desarrollo inmobiliario. En varios casos, la negociación busca acuerdos sobre los 
beneficios económicos y materiales, es decir, el pago de las externalidades negativas que las intervenciones produzcan en los recursos patrimoniales; así, una vez logrado el acuerdo, la obra o proyecto se realiza.

Las necesidades de las comunidades étnicas conllevan prácticas de aprovechamiento que cuestionan la estabilidad del bosque y los servicios hídricos: cambios de uso de suelo forestal a usos agrícola y urbano, incendios forestales, tala clandestina, extracción de leña para consumo y venta. Los impactos ecosistémicos de las intervenciones externas y las prácticas de aprovechamiento de los grupos étnicos se manifiestan en erosión del suelo, deforestación, alteración de la dinámica hidrológica de las corrientes superficiales y afloramientos subterráneos que regulan la disponibilidad de agua para consumo humano, lo que repercute en el ciclo vital de las Ciénegas de Lerma y ratifica la vulnerabilidad hídrica del valle de Toluca.

En el área de influencia de la Ciénega de Chignahuapan, la mixtura de modos de vida caracteriza la recomposición de los roles y las conductas individuales para adaptarse a los cambios ambientales. Las economías domésticas de obreros y empleados representan la transformación de las actividades productivas y la consolidación del modo de vida urbano. Los campesinos-pastores y las actividades estacionales de los recolectores, pescadores, cazadores y cazador-pescador mantienen la reminiscencia de un modo de vida agrario y lacustre que complementa el círculo de subsistencia de grupos vulnerables.

Las fortalezas están en las propiedades ecológicas y en la biodiversidad del cuerpo lacustre: el espejo de agua, las zonas someras de los fangales y el pantano, la diversidad florística y la producción primaria de plantas acuáticas y subacuáticas, aves nativas y migratorias que anidan y se desarrollan en el área.

Si bien las UMAS se concibieron como estrategias que ofrecerían diversificación productiva mediante la conservación y el aprovechamiento del ecosistema lacustre y la cacería deportiva coadyuvante de desarrollo comunitario a través del empleo y los ingresos, las debilidades denotan fragmentación tanto de los derechos de propiedad en cinco unidades de aprovechamiento cinegético como de los intereses individuales, en los que priva la desconfianza y la ausencia de acuerdos sobre mejoras del aprovechamiento.

Los conflictos por el control, la apropiación y el aprovechamiento de los recursos lacustres caracterizan la ambigüedad en los usos permitidos, el aprovechamiento cinegético inconmensurable, la inequitativa distribución de los beneficios económicos y la extracción por parte de sectores de población de bajos recursos.

Las oportunidades se desprenden de la condición de área protegida y de la importancia internacional, así como del humedal Ramsar y del hábitat de aves migratorias. Respecto al seguimiento y al cumplimiento de la operación sustentable de la interfase agua-tierra y al aprovechamiento cinegético sobre los acuerdos, se podrían realizar gestiones de pago por servicios ambientales a través de proyectos de captura de carbono y belleza escénica. 
Las amenazas expresan la creciente presión demográfica, la re densificación de localidades en la sierra, el pie de monte y planicie en localidades ribereñas de origen agrario y los asentamientos irregulares, la elevada tasa de crecimiento anual de la población, la inmigración, la infraestructura vial regional y la descarga de aguas residuales. Asimismo, agentes externos participan en la transferencia de usufructo por dinero en la actividad cinegética a través del arrendamiento; no sólo trasfieren temporalmente la propiedad y los derechos de manejo cinegético, sino también la responsabilidad y los compromisos para mantener y conservar el hábitat de especies residentes y migratorias. Se sabe por qué rentan, pero no se sabe a quién ni si el arrendamiento establece criterios que garanticen la conservación del hábitat y la biodiversidad.

\section{Conclusiones}

Las externalidades ambientales regionales y locales que alteran la capacidad de la Ciénega de Chignahuapan para absorber la presión ambiental y mantener sus funciones ecosistémicas vitales se expresan en los cambios de uso de suelo, la alteración del ciclo del agua que desciende de la montaña, la disminución de los servicios hídricos del bosque, la contaminación de afluentes, la construcción de vialidades regionales, la actividad industrial, la re densificación demográfica, la urbanización y la sub urbanización.

Las dinámicas locales se observaron en la alteración del régimen hidrológico debido a la construcción de bordos y desvío de agua para las tierras de cultivo, quema de tule, contaminación por descargas residuales crudas de origen municipal e industrial que ocasionan diminución de oxígeno disponible necesario para flora y fauna acuáticas, transferencia de los derechos de usufructo de la actividad cinegética y aprovechamiento de subsistencia; así como la proliferación de malezas terrestre y acuática, como algas en aguas profundas y lirio acuático en las zanjas, introducción de especies exóticas depredadoras y alta capacidad de reproducción -carpa tilapia-. Las quemas de tule convertidas en incendios ocasionan efectos negativos de alto impacto, pero se carece de estudios específicos sobre las motivaciones sociales que inducen estas prácticas y los efectos en la biodiversidad.

Los parámetros de calidad del agua en la Ciénega en estudio, la demanda bioquímica de oxígeno, los sólidos suspendidos, los coliformes y la demanda química de oxígeno muestran que la contaminación es un fenómeno difuso y de complejidad creciente. Los valores bajos de sólidos suspendidos y toxicidad identifican que el agua superficial mantiene una calidad de excelente a buena para que la vida de las comunidades acuáticas se desarrolle. Los valores de la demanda química de oxígeno, en correlación con elevados contenidos de materia orgánica, colocan el agua en las categorías de contaminada a fuertemente contaminada, sobre todo por la descarga de aguas residuales crudas de origen municipal e industrial. 
La presión del entorno en mediano plazo anticipa un escenario desalentador: fragmentación del hábitat natural, pérdida de vegetación acuática y subacuática e incremento de las descargas de aguas residuales crudas que anularían las formas de vida natural. Las medidas de protección carecen de estrategias y adolecen de deficiencias presupuestales y operativas para regular los intereses individuales, derivados de la naturaleza jurídica de la propiedad de los recursos lacustres, las necesidades de grupos vulnerables y la creciente actividad industrial y urbana. La degradación del bosque, del agua y de los recursos lacustres se justifica a través de una política de protección inconsistente que legitima el crecimiento económico de la región del alto Lerma y anticipa la espiral descendente de la capacidad de recuperación natural del ecosistema lentico para catalizar las externalidades ambientales y mantener sus funciones vitales.

La visión sostenible prescribe mitigar la contaminación del agua y evitar la extinción de los recursos lacustres mediante estrategias de colaboración, autogestión y regulación, con el objeto de que las industrias acaten la responsabilidad social de acuerdo con su actividad y tomen medidas para tratar el agua servida que evacuan. Los gobiernos deben incrementar la capacidad instalada para tratar el creciente volumen de las aguas residuales municipales y los usuarios deben mejorar el uso y el cuidado del agua. En las unidades de manejo, se requiere monitorear las acciones de conservación y manejo, aplicar sanciones en materia cinegética y prácticas ilegales, regular el arrendamiento cinegético por terceros y desarrollar proyectos de recuperación del conocimiento tradicional y de restauración ecológica.

\section{Agradecimientos}

A la Universidad Autónoma del Estado de México y al Consejo Nacional de Ciencias y Tecnología por el apoyo a través de los proyectos 107956 y 4742/2019CIB.

\section{Referencias}

Albores, B. A. (1995). Tules y sirenas: el impacto ecológico y cultural de la Industrialización del Alto Lerma. México. Toluca, México: El Colegio Mexiquense.

Ávila, A. (2017). Sistema Cutzamala en 20 años comenzará su agotamiento. Periódico Milenio. Disponible en http://www.milenio.com/estados/sistema-cutzamala-20-anos-comenzara-agotamiento

Cadena, C., \& Salgado, L. (2017). Redes y capacidades de actores en torno a comités independientes de agua potable: el caso de San Felipe Tlalmimilolpan, Toluca, México. Revista de El Colegio de San Luis, VII (13), 62-90. http:/ / dx.doi.org/10.21696/rcsl7132017635

Camacho, G. (2007). Agua y liberalismo. El proyecto estatal de desecación de las lagunas del Alto Lerma, 1850-1875. Distrito Federal, México: CIESAS, CONAGUA.

Ceballos, G. (2003). Ficha Informativa de los Humedales de RAMSAR. México, México: CONANP.

CEPANAF. (2019). Ficha técnica del Área Natural Protegida Ciénegas de Lerma. Recuperado de http://cepanaf.edomex.gob.mx/decretos_areas_naturales_protegidas. 


\section{AÑO 22, 2020-1 ENERO-JUNIO E-ISSN 2594-102X PÁGS. 5-33 IUH:Ë.}

CONAFOR (2017). Descripción de la Problemática Área de Protección de Flora y Fauna Ciénegas de Lerma. México, México: SEMARNAT. Recuperado de cofemersimir.gob.mx/expediente/19983/mir/41296/anexo/3280671 · Archivo PDF

CONAFOR. (2011). Ficha 1335. RAMSAR. Ciudad de México, México: CONAFOR. Recuperado de http://ramsar.conanp.gob.mx/docs/sitios/FIR_RAMSAR/Estado_de_Mexico/Cienegas_de_Lerma/ Ci\%C3\%A9negas\%20de\%20Lerma.pdf

CONAGUA. (2016). Red de Monitoreo de Calidad del Agua en México, Calidad del agua superficial. México, México: CONAGUA. Recuperado de http://www.gob.mx/conagua/documentos/monitoreo-de-la-calidaddel-agua-en-mexico

CONAGUA. (2012-2108). Base de datos por Estados, Calidad del agua en México. Recuperado de https://www.gob.mx/conagua/articulos/calidad-del-agua,consulta 11-12-2019

CONAPO. (2016). México. Proyección de la población de los municipios 2010-2030. México, México: CONAPO. Recuperado de http://www.conapo.gob.mx/es/CONAPO/Proyecciones_Datos/

Cortés, G. (2014). Deterioro del bosque templado en la comunidad de San Lorenzo Huitzizilapan, municipio de Lerma, Estado de México. Toluca, México. Universidad Autónoma del Estado de México.

DOF (2002). Decreto del área natural protegida, con el carácter de área de protección de flora y fauna, la región conocida como Ciénegas del Lerma. México, México: SEMARNAT

DOF. (2000). Ley General de Vida Silvestre. México, México: Cámara de Diputados del H. Congreso de la Unión. Secretaría General. Recuperado de http://www.diputados.gob.mx/LeyesBiblio/ref/lgvs.htm

DOF. (1998). Ley General de Equilibrio Ecológico y Protección al Ambiente. México, México: Presidencia de la República, Comisión Nacional de Áreas Naturales Protegidas.

H. Ayuntamiento de Metepec. (2016). Plan de desarrollo municipal de Metepec 2016-2018. Gaceta Municipal. Órgano oficial de Gobierno Municipal de Metepec, Metepec, México, Año 1, No. 31, 30 de marzo.

H. Ayuntamiento de Lerma. (2013). Plan de desarrollo municipal de Lerma 2013-2015, Gaceta Municipal. Periódico oficial de Gobierno Municipal de Lerma, Lerma, México, nueva época 07, miércoles 10 abril.

Galli, A.; Katsunorilha; M.; El Bilali, H.; Grunewald, N.; Eaton, D.; Capone, R.; Debs, P.; Bottalico, F. (2017). Mediterranean countries' food consumption and sourcing patterns: An Ecological Footprint viewpoint. Science of The Total Environment. Volume 578, 383-391. Recuperado de https://www.sciencedirect.com/science/article/pii/S0048969716323816?via\%3Dihub

Gálvez, J. (2012). Política Ambiental implícita. Plaza Pública. Recuperado de https://www.plazapublica.com.gt/content/ politica-ambiental-implicita

GEM. (2010). Inventario Forestal 2010. Toluca, México: PROBOSQUE.

GEM. (2003). Plan Municipal de Desarrollo Urbano de Lerma. Toluca, México: Secretaría de Desarrollo Urbano y Vivienda.

GEM. (1993). Atlas Ecológico de la Cuenca Hidrografica del Rio Lerma. Tomo I. Toluca, México: Comisión para la Recuperación de la Cuenca Alta del Río Lerma.

GEM. (1969). Dotación de Tierras Ejidales Comprendidas de 1919 a 1968. Toluca, México: Dirección de Agricultura y Ganadería.

Gibert, J. y Correa, B. (2001). La teoría de la autopoiesis y su aplicación en las ciencias sociales. Cinta moebio 12: 175-193. Recuperado de www.moebio.uchile.cl/12/gibert.htm

Giménez, G. (1999). La Investigación Cultural en México. Una aproximación. Perfiles Latinoamericanos, 15, 119138, Distrito Federal, México: Facultad latinoamericana de Ciencias Sociales.

González, A.; Velasco, J.J. (2015). La muerte de un humedal. Ambiente y Cultura en la Cuenca alta del río Lerma. México, México: Alpe Ediciones,

Flores, G. (2009). Variación morfológica de Aztecula Sallaei del Alto Lerma: implicaciones taxonómicas y de conservación. Toluca, México. Universidad Autónoma del Estado de México.

Hatch, G.; Schmidt, S.; Carrillo, J. J. (2017). Elementos de análisis de la propuesta de Ley General de Aguas en México a partir del Derecho Humano al agua y sus repercusiones en el quehacer científico, Revista de El Colegio de San Luis, VII (13), 30-61. http:/ / dx.doi.org/10.21696/rcsl7132017668 
Hernández, R.; Fernández, C. \& Baptista, P. (2006). Metodología de la Investigación. México, México: McGraw Hill: Interamericana Editores.

Ibarra, M. V. (2010). El uso hegemónico del agua en la laguna Chignahuapan 1940-1969. Revista mexicana de ciencias políticas y sociales, 52(208), 113-131. Recuperado de http://www.scielo.org.mx/scielo.php?script=sci_arttext\&pid=S018519182010000100007\&lng=es\&tlng $=$ es.

INEGI. (2017). Directorio Estadístico Nacional de Unidades Económicas (DENUE), Aguascalientes, México: INEGI. Recuperado de https://www.inegi.org.mx/app/statisticsexplorer/15/index.html

INEGI. (2010). Estado de México. Resultados definitivos del Censo de Población, 2010. Aguascalientes, México.

INEGI. (2000). Tabulados Básicos Nacionales y por Entidad Federativa. Base de datos y Tabulados de la Muestra Censal. XII Censo General de Población y Vivienda, 2000. Aguascalientes, México.

INE. (2003). Diagnostico biofísico y socioeconómico de la cuenca Lerma-Chapala, Distrito Federal. México: Dirección de Investigación de Ordenamiento Ecológico y Conservación de Ecosistemas. Dirección de Manejo Integral de Cuencas Hídricas.

Maturana, H.; Varela, J. F. (2007). La autopoiesis de Maturana y Varela: ¿Seres sociales o seres individuales? Recuperado

de http://www.johndeweycollege.cl/cms/UPIMGS/archivos/CON_172/_VARELA.pdf

Martínez, J. (2004). Los conflictos ecológico-distributivos y los indicadores de sustentabilidad. Revista Iberoamericana de Economía Ecológica. Vol. 1: 21-30.

Miró, P. (2002). El Teorema de Coase y sus implicaciones según. El problema del Coste Social, en Contribuciones a la economía de La Economía de Mercado, virtudes e inconvenientes. Recuperado de http://www.eumed.net/cursecon/colaboraciones/index.htm

Patrick, G A. (2012). Ecología y cultura lacustres en Almoloya del Río, 1900-2004. Distrito Federal. México: Universidad Autónoma Metropolitana.

PROFEPA. (2010). Operativo contra cacería ilegal en las Ciénegas de Lerma, México. Distrito Federal, México: PROFEPA. Recuperado de http://www.profepa.gob.mx/innovaportal/v/3455/1/mx.wap/operativo_contra_caceria_ilegal_en_ las_cienegas_de_lerma_mex.html

Quintero, A. (2016). Apropiación de la naturaleza en una comunidad afrodescendiente del Pacífico colombiano: Un modelo de flujos de bienes. Revista Iberoamericana de Economía Ecológica. Vol. 25: 0115. Redibec. URL: http://www.redibec.org/IVO/rev25_01.pdf

Rathe, L. (2017). La sustentabilidad en los sistemas socio-ecológicos. Utopía y Praxis Latinoamericana, 22 (78), 6578. Recuperado

de: https://produccioncientificaluz.org/index.php/utopia/article/view/22635/22444

Robledo, D. (1997). Las algas y la biodiversidad. Biodiversitas. 13: 1-4, México: CONABIO.

Rojas, T. (1991). La agricultura en tierras mexicanas desde sus orígenes hasta nuestros días. Distrito Federal, México: Consejo Nacional para la Cultura y las Artes. Grijalbo.

Romero, J. (1974). Almoloyan. Su río y puentes coloniales. Su acueducto. Toluca, México. Gobierno del Estado de México.

Rzedowski, J. (1983). Vegetación de México. México,México: Limusa.

SACMEX (2016). El gran reto del agua en la ciudad de México. Pasado, presente, prospectivas de solución para una de las ciudades más complejas del mundo. Recuperado de http://laopiniondelaciudad.mx/wpcontent/uploads/2016/02/ElGranRetodelAgua_enla_CiudadMexico.pdf

Salazar, C. (2000). La relación de la población y los recursos naturales en un área de expansión de la ciudad de México. Estudios Demográficos y Urbanos, 44: 287-324. Recuperado de: http://dx.doi.org/10.24201/edu.v15i2.1077

SEMARNAT. (2018). Agua - calidad. Indicadores básicos de Desempeño Ambiental México. Recuperado de https://apps1.semarnat.gob.mx:445/dgeia/indicadores14/conjuntob/02_agua/02_calidad_esquema. html 
SEMARNAT. (2002). Decreto por el que se declara área natural protegida, con el carácter de área de protección de flora y fauna, la región conocida como Ciénegas del Lerma: México. Distrito Federal. México: SEMARNAT.

Sugiura, Y. (2000). Cultura lacustre y sociedad del valle de Toluca. Revista Arqueología Mexicana. Serie Tiempo Mesoamericano, 8-43: 32-43.

Sugiura, Y. (1998). La caza, la pesca y la recolección: etnoarqueología del modo de subsistencia lacustre en las Ciénegas del Alto Lerma. Distrito Federal. México: Universidad Nacional Autónoma de México.

Velasco, J. J. (2008). La Ciénaga de Chiconahuapan, Estado de México: un humedal en deterioro constante. Contribuciones desde Coatepec, 15: 101-122. Recuperado de: http://ri.uaemex.mx/bitstream/handle/20.500.11799/38787/La\%20Ciénaga\%20de\%20Chiconahuap an, $\% 20$ Estado\%20de\%20México-

$\%$ 20un $\% 20$ humedal $\% 20 \mathrm{en} \% 20$ deterioro\%20constante.pdf?sequence $=1$

Villalba, C. (2004). El Concepto de Resiliencia. Aplicaciones en la Intervención Social. Departamento de Trabajo Social y Ciencias Sociales. Sevilla: Universidad Pablo de Olvide.

WWF. (2016). Informe planeta vivo 2016. Riesgo y resiliencia en una nueva era. Gland, Suzie, WWF, International, Institute of Zoology Zoological Society of London Regent's Park; Global Footprint Network. Recuperado de http://www.wwf.org.mx/quienes_somos/informe_planeta_vivo/

Young, A. A. (2009). Rendimientos crecientes y progreso económico. Revista de Economía Institucional, (11) 21: 227-243. Recuperado de: https://revistas.uexternado.edu.co/index.php/ecoins/article/view/376/354

Zepeda, C., Némiga, X, Lot, A.; Madrigal, D. (2012a). Análisis del cambio del uso del suelo en las Ciénegas de Lerma (1973-2008) y su impacto en la vegetación acuática, Investigaciones Geográficas (Mx), 78: 48-61. http://dx.doi.org/10.14350/rig.32469

Zepeda, C., Némiga, X, Lot, A.; Madrigal, D. (2012b). Florística y diversidad de las Ciénegas del río Lerma Estado de México, México, Acta Botánica Mexicana 98: 23-49. https://doi.org/10.21829/abm98.2012.1139 